\title{
A Neurovisceral Approach to Autism: Targeting Self- Regulation and Core Symptoms Using Neurofeedback and Biofeedback
}

\author{
Matthew S. Goodman ${ }^{1,2}$, Nicolette Castro ${ }^{2}$, Mary Sloan $^{2}$, Rita Sharma ${ }^{1,2}$, Michael Widdowson², \\ Eduardo Herrera ${ }^{2}$, and Jaime A. Pineda ${ }^{2,3^{*}}$ \\ ${ }^{1}$ California School of Professional Psychology at Alliant International University, San Diego, California, USA \\ ${ }^{2}$ Department of Cognitive Science, University of California, San Diego, California, USA \\ ${ }^{3}$ Neurosciences Group, University of California, San Diego, California, USA
}

\begin{abstract}
Mu Rhythm Synchrony Neurofeedback (MRS-NFB) has shown promise in improving electrophysiological and behavioral deficits in autism spectrum disorder (ASD). Heart rate variability biofeedback (HRV-BFB), a method for improving self-regulation of the autonomic nervous system (ANS), has yet to be tested as a clinical intervention for ASD. This study evaluated the impact of HRV-BFB on symptoms of ASD; and whether a combined HRV-BFB + MRS-NFB intervention would be more efficacious than HRV-BFB alone. Fifteen children with a verified diagnosis of ASD completed the study. Participants were assigned to either an HRV-BFB group (Group 1) or a combined HRV-BFB + MRS-NFB group (Group 2). All children underwent pre- and postassessments of electroencephalography (EEG), heart rate variability (HRV), and parent-reported behaviors. No significant between-groups differences were observed on any parent-reported behaviors. Group 1 showed significant pre-post improvements in emotion regulation and social behavior, while Group 2 showed significant pre-post improvements in emotional lability and autistic behaviors. Group 2 also showed significant improvements in RMSSD and InHF (vagal tone) indices of HRV over time, while Group 1 displayed no significant changes in HRV over time. Group 1 showed an increase in mu suppression posttraining, and Group 2 showed a reduction in mu suppression posttraining. The results suggest that HRV-BFB, alone or in combination with MRSNFB, may improve behavioral features of autism. A combined approach may be more efficacious in enhancing HRV, while the implications of each approach on mu suppression are mixed. Neurovisceral approaches that teach self-regulation offer a novel treatment avenue for ASD.
\end{abstract}

Keywords: autism; neurofeedback; biofeedback; heart rate variability; mu rhythms; mirror neuron system; neurovisceral integration

Citation: Goodman, M. S., Castro, N., Sloan, M., Sharma, R., Widdowson, M., Herrera, E., \& Pineda, J. A. (2018). A neurovisceral approach to autism: Targeting self-regulation and core symptoms using neurofeedback and biofeedback. NeuroRegulation, 5(1), 9-29. http://dx.doi.org/10.15540/nr.5.1.9

*Address correspondence to: Jaime A. Pineda, PhD, Department of Cognitive Science, University of California, San Diego, 9500 Gilman Drive, La Jolla, CA 92093-0515, USA. Email: pineda@cogsci.ucsd.edu

Copyright: (־ 2018. Goodman et al. This is an Open Access article distributed under the terms of the Creative Commons Attribution License (CC-BY).
Edited by:

Rex L. Cannon, PhD, Knoxville Neurofeedback Group, Knoxville Tennessee, USA

Reviewed by:

Wesley D. Center, PhD, Liberty University, Lynchburg, Virginia, USA Randall Lyle, PhD, Mount Mercy University, Cedar Rapids, Iowa, USA
Autism spectrum disorder (ASD) is characterized by social impairments and restricted, repetitive behaviors, in addition to broader deficits in executive functioning, emotion regulation, and the presence of comorbid disorders like anxiety (American Psychiatric Association, 2013; Hill, 2004; Mazefsky et al., 2013; White, Oswald, Ollendick, \& Scahill, 2009). In the past decade, neurobiological explanations of ASD have expanded from identifying regional brain impairments (e.g., amygdala, fusiform face area; Adolphs, Sears, \& Piven, 2001; Schultz et al., 2003) to focusing on networks, including the interaction of multiple networks (e.g., Default Mode Network [DMN], Salience Network [SN], and Executive Control Network [ECN]; Kennedy, Redcay, \& Courchesne, 2006; Uddin \& Menon, 
2009). It is argued that impairments may result not so much from aberrant anatomy but from alterations in functional connectivity within and across networks, defined as interregional correlations in the time-course of the fMRI blood oxygenation leveldependent (BOLD) signal (Biswal, Yetkin, Haughton, \& Hyde, 1995; Vissers, Cohen, \& Geurts, 2012). These atypical patterns of functional connectivity may underlie the disordered and idiosyncratic information integration that is characteristic of the ASD brain, accounting for the myriad symptoms along the autism spectrum (Belmonte et al., 2004; Brock, Brown, Boucher, \& Rippon, 2002).

One network proposed to exhibit the hyper- and hypoconnectivity characteristic of ASD, and which might contribute specifically to deficits in the social domain, is the human Mirror Neuron System (MNS; Fishman, Keown, Lincoln, Pineda, \& Müller, 2014; Shih et al., 2010). The MNS consists of a group of frontoparietal regions associated with imitation and empathic behavior (di Pellegrino, Fadiga, Fogassi, Gallese, \& Rizzolatti, 1992; lacoboni, 2009; Williams et al., 2006). Desynchronization or suppression of electrophysiological oscillations over the sensorimotor cortex, known as mu rhythm (alpha mu: $8-13 \mathrm{~Hz}$; beta mu: $15-25 \mathrm{~Hz}$ ) and recorded with electroencephalography (EEG), has been hypothesized to indirectly reflect MNS activity (Cochin, Barthelemy, Roux, \& Martineau, 1999; Pineda, Allison, \& Vankov, 2000; for a review see Pineda, 2005). While the MNS theory of autism has been a subject of debate (Enticott et al., 2013; Hamilton, 2013), it is generally agreed that mu rhythms are linked to the MNS and that both are involved in imitation and social behavior (Bernier, Aaronson, \& McPartland, 2013; Braadbaart, Williams, \& Waiter, 2013; Pineda, 2008). In typically developing (TD) individuals, suppression of this rhythm occurs during self-initiated motor actions and when observing another individual's meaningful action (i.e., "mirroring"; Gallese, Fadiga, Fogassi, \& Rizzolatti, 1996). In children with autism, however, this suppression occurs during self-movement (execution), but not while observing others move (Oberman et al., 2005). Furthermore, the observation deficit in ASD disappears when observing familiar, as opposed to unfamiliar, individuals (Oberman, Ramachandran, \& Pineda, 2008). This has led researchers to conclude that under certain circumstances the MNS is functional and therefore to test clinical applications like neurofeedback that seek to remediate mu rhythm dysfunction in ASD.
Neurofeedback uses brain-computer interface technology to teach self-regulation of endogenous brain rhythms through principles of operant conditioning. Real-time display of EEG activity rewards the participant for modulating power in specific neurophysiological rhythms. A variety of neurofeedback interventions have led to improvements in attention, executive functioning, language, and social behavior in children with ASD (Coben, Linden, \& Myers, 2010; Coben \& Padolsky, 2007; Kouijzer, van Schie, de Moor, Gerrits, \& Buitelaar, 2010). Mu Rhythm Synchrony Neurofeedback (MRS-NFB), which specifically focuses on training mu rhythms, has shown promise in reducing core symptoms of autism, including language, social cognition, and emotional responsiveness (Friedrich et al., 2015; Pineda, Carrasco, Datko, Pillen, \& Schalles, 2014; Pineda et al., 2008). Note that while MRS-NFB aims to train the frequency and amplitude of centro-parietal rhythms, it does not train the morphology of the waveform itself. Previous studies of MRS-NFB in ASD have focused on enhancing mu power during training, as it is thought that the ability to enhance $\mathrm{mu}$ is a prerequisite for being able to perform $\mathrm{mu}$ suppression (Pineda, 2005; Pineda et al., 2008; Pineda, Carrasco, et al., 2014). One recent study trained children with ASD to either a) increase mu power, or b) increase and decrease mu power via a NFB paradigm utilizing a social video game. Children in both groups learned to regulate mu rhythms and did not significantly differ in the ability to suppress mu at the end of the training (Friedrich et al., 2015). Thus, the current study continued the protocol of mu enhancement.

While much attention has been given to central nervous system (CNS) dysfunction in ASD, the role of the peripheral nervous system (PNS) has also begun to attract interest. Porges $(2001,2003,2007)$ initially proposed the Polyvagal Theory to describe how the vagus nerve (specifically its phylogenetically-recent myelinated pathway) mediates social behavior in mammals; and thus, how vagal dysfunction may contribute to social disorders like autism. The vagus is the 10th cranial nerve and helps regulate autonomic nervous system (ANS) activity via connections to the heart and other visceral organs. It is anatomically and functionally involved in the Social Engagement System (e.g., gaze, facial expression, extraction of the human voice, prosody), whereby dysfunction is hypothesized to mediate social withdrawal behaviors in autism; and regulates maladaptive defense strategies (e.g., fight-or-flight or immobilization and shutdown) and self-soothing (e.g., repetitive) 
behaviors, also characteristic behavioral patterns of ASD (Porges, 2003). The vagus controls heart rhythms through inhibitory (parasympathetic) slowing of the heart, and disinhibitory (sympathetic) speeding up of the heart. These beat-to-beat fluctuations are referred to as heart rate variability (HRV) and are used as a measure of self-regulation and healthy ANS functioning (McCraty \& Shaffer, 2015). Studies have shown that children with ASD have lower baseline HRV compared to controls (Bal et al., 2010; Van Hecke et al., 2009). Within the ASD population, those with higher HRV demonstrate superior emotion recognition, receptive language skills, social behavior, and caregiver-reported language and cognitive abilities (Bal et al., 2010; Patriquin, Lorenzi, \& Scarpa, 2013; Patriquin, Scarpa, Friedman, \& Porges, 2011). Therefore, there is incentive for researchers to investigate mechanisms that might enhance HRV in ASD.

HRV biofeedback (HRV-BFB) is a widely supported intervention for improving HRV and overall ANS functioning (Lehrer et al., 2006; Lin et al., 2012; Siepmann, Aykac, Unterdörfer, Petrowski, \& MueckWeymann, 2008). While its clinical benefits have been demonstrated across a range of disorders, no known studies have examined HRV-BFB in the ASD population. HRV-BFB allows patients to see their fluctuating heart rhythms, in real-time, while practicing resonant frequency (RF) diaphragmatic breathing. RF refers to the unique breath rate, typically between 4.5 and 7.0 breaths per minute (bpm), where HRV is maximized due to "resonance" between ANS functions like the breath, baroreceptors, and vagal control of the heart (Lehrer, Vaschillo, \& Vaschillo, 2000).

HRV may also be a reflection of social behavior based on the principle of neurovisceral integration (Thayer \& Lane, 2000). Not only do CNS regions influence ANS activity through vagally mediated efferent pathways, but visceral regions also send afferent information back up to the brain. This bidirectional, integrated system is known as the Central Autonomic Network (CAN; Benarroch, 1993). Some regions in this network, such as the amygdala, insula, anterior cingulate, and orbitofrontal cortex, overlap with networks related to attentional, affective, and social processing that are thought to play a role ASD (Di Martino et al., 2009; Kana, Keller, Minshew, \& Just, 2007; Sabbagh, 2004; Uddin \& Menon, 2009). Through inhibitory, feedback, and feedforward loops, this system maintains homeostatic balance across the CNS and PNS; and disruption within these circuits leads to impairments in cognition and clinical symptoms
(Thayer \& Brosschot, 2005; Thayer, Hansen, SausRose, \& Johnsen, 2009). Therefore, interventions like HRV-BFB not only act on the PNS but may also influence CNS functioning as well.

Given evidence of both CNS and PNS dysfunction in ASD, interventions that target both "top-down" and "bottom-up" deficits might be more beneficial than either approach used alone. By improving global, underlying self-regulatory mechanisms, a broader range of behaviors beyond those targeted by standard behavioral interventions might be addressed, including self-stimulatory and repetitive behaviors, attention, and emotion regulation. Other comorbid diagnoses, such as anxiety, might also be impacted. The purpose of the current study was first, to evaluate the effect of HRV-BFB on symptoms of autism; and second, to evaluate whether a combination of HRV-BFB and MRS-NFB (HRV-BFB + MRS-NFB) is more effective than HRVBFB alone. It was hypothesized that HRV-BFB would lead to improvements in autistic symptoms, social behavior, emotion regulation, anxiety, and HRV. Similarly, it was hypothesized that HRV-BFB + MRS-NFB would lead to improvements in autistic symptoms, social behavior, emotion regulation, anxiety, HRV, as well as mu suppression. Finally, it was speculated that HRV-BFB + MRS-NFB would lead to greater improvements in all of these domains than HRV-BFB alone.

\section{Methods}

\section{Participants}

A total of 15 children with ASD completed the study. Participants were recruited through Valerie's List (an online community providing autism-related support and resources), word of mouth, and a large metropolitan school district in southern California (approval was granted through the district's research review panel). The University of California, San Diego IRB approved this experiment. Informed consent was obtained from all individual participants included in the study.

Of the 15 subjects, 13 were male and 2 were female. Ages ranged from 9 to 18 years $(M=12.4$, $S D=2.5$ ). All subjects underwent diagnostic verification by a trained clinical psychologist using the Autism Diagnostic Observation Schedule, Second Edition (ADOS-2; Lord et al., 2012), Wechsler Abbreviated Scale of Intelligence, 2nd Edition (WASI-II; McCrimmon \& Smith, 2013), and Autism Diagnostic Interview-Revised (ADI-R; Lord, Rutter, \& Le Couteur, 1994). See Table 1 and Table 
2 for complete demographic and diagnostic information.

A minimum IQ score was not required for inclusion, and scores ranged from extremely low to superior. The inclusion/exclusion criteria were as follows: 1) children must be 6-18 years old; 2) participants must be able to perform the diaphragmatic breathing technique (see Preliminary HRV Biofeedback Training section), as it is an integral component of HRV-BFB. Participants who could not evidence this ability by the second session were excluded; and 3) children must be able to tolerate EEG procedures (e.g., electrodes and gel being placed on head), or they were otherwise excluded from the study.

\section{Table 1}

Demographic characteristics of HRV-BFB Only and HRV-BFB + MRS-NFB groups.

\begin{tabular}{lccc}
\hline & $\begin{array}{c}\text { Group 1 } \\
\text { HRV-BFB Only } \\
(\boldsymbol{n}=\mathbf{7})\end{array}$ & $\begin{array}{c}\text { Group 2 } \\
\text { HRV-BFB + MRS-NFB } \\
(\boldsymbol{n}=\mathbf{8})\end{array}$ & $\begin{array}{c}\text { Group 1 + Group 2 } \\
\text { Combined } \\
(\boldsymbol{N}=\mathbf{1 5})\end{array}$ \\
\hline Gender (\% Male) & $85.7 \%$ & $87.5 \%$ & $86.7 \%$ \\
Age - Mean (SD) & $12.1(2.3)$ & $12.8(2.8)$ & $12.5(2.5)$ \\
Race/Ethnicity & & & \\
$\quad$ White/Caucasian & 3 & 4 & 7 \\
$\quad$ Asian/Asian-Pacific Islander & 1 & 0 & 1 \\
Hispanic/Latino & 1 & 3 & 4 \\
$\quad$ Mixed White/Asian/Hispanic & 1 & 0 & 1 \\
$\quad$ Mixed African-American/Asian & 1 & 0 & 1 \\
$\quad$ Mixed White/Hispanic & 0 & 1 & 1 \\
Medication (\%) & $42.9 \%$ & $14.3 \%$ & $26.7 \%$ \\
\hline
\end{tabular}

\section{Table 2}

Diagnostic data of HRV-BFB Only and HRV-BFB + MRS-NFB groups.

\begin{tabular}{|c|c|c|c|c|}
\hline & $\begin{array}{c}\text { ASD } \\
\text { Cut-offs }\end{array}$ & $\begin{array}{c}\text { Group 1 } \\
\text { HRV-BFB Only } \\
\begin{array}{c}(n=7) \\
\text { Mean (SD) }\end{array}\end{array}$ & $\begin{array}{c}\text { Group 2 } \\
\text { HRV-BFB } \\
+ \text { MRS-NFB } \\
(n=8) \\
\text { Mean }(S D) \\
\end{array}$ & $\begin{array}{c}\text { Group } 1+\text { Group } 2 \\
\text { Combined } \\
(N=15) \\
\text { Mean }(S D)\end{array}$ \\
\hline \multicolumn{5}{|l|}{ WASI-II } \\
\hline Full Scale IQ & & $94.4(14.6)$ & $87.3(19.2)$ & $90.6(17.0)$ \\
\hline Verbal Comprehension Index & & $92.1(19.7)$ & $79.6(21.0)$ & $85.5(20.7)$ \\
\hline Perceptual Reasoning Index & & $102.9(13.9)$ & $99.7(18.3)$ & $101.3(15.7)$ \\
\hline \multicolumn{5}{|l|}{ ADOS-II } \\
\hline Communication & 2 & $5.0(1.8)$ & $5.6(2.3)$ & $5.3(2.0)$ \\
\hline Reciprocal social interaction & 4 & $9.3(1.9)$ & $10.9(2.9)$ & $10.1(2.5)$ \\
\hline Communication and social interaction & 7 & $14.3(3.4)$ & $16.4(5)$ & $15.4(4.3)$ \\
\hline Imagination/Creativity & - & $1.1(0.7)$ & $1.3(0.8)$ & $1.2(.73)$ \\
\hline Stereotyped behaviors and restricted interests & - & $3.6(1.5)$ & $3.1(1.8)$ & $3.4(1.6)$ \\
\hline
\end{tabular}




\section{Table 2}

Diagnostic data of HRV-BFB Only and HRV-BFB + MRS-NFB groups.

\begin{tabular}{|c|c|c|c|c|}
\hline & $\begin{array}{l}\text { D } \\
\text { offs }\end{array}$ & $\begin{array}{c}\text { Group } 1 \\
\text { HRV-BFB Only } \\
\begin{array}{c}(n=7) \\
\text { Mean (SD) }\end{array}\end{array}$ & $\begin{array}{c}\text { Group } 2 \\
\text { HRV-BFB } \\
+ \text { MRS-NFB } \\
(n=8) \\
\text { Mean }(S D)\end{array}$ & $\begin{array}{c}\text { Group } 1+\text { Group } 2 \\
\text { Combined } \\
(N=15) \\
\text { Mean }(S D)\end{array}$ \\
\hline \multicolumn{5}{|l|}{ ADI-R } \\
\hline Qualitative abnormalities in reciprocal social interaction & 10 & $15.3(2.9)$ & $18.1(6.3)$ & $16.7(4.9)$ \\
\hline Qualitative abnormalities in communication (verbal) & 8 & $11.6(2.1)$ & $13.3(6.3)$ & $12.4(4.6)$ \\
\hline $\begin{array}{l}\text { Qualitative abnormalities in communication } \\
\text { (non-verbal) }\end{array}$ & 7 & $8.0(1.5)$ & $10.6(2.1)$ & $9.3(2.2)$ \\
\hline Restricted, repetitive and stereotyped behaviors & 3 & $5.7(2.2)$ & $5.0(2)$ & $5.4(2.1)$ \\
\hline Abnormality of develop evident before 36 months & 1 & $3.1(0.4)$ & $3.6(1.1)$ & $3.4(.84)$ \\
\hline
\end{tabular}

\section{Procedure}

Participants were assigned to either the HRV-BFB group (Group 1) or HRV-BFB + MRS-NFB group (Group 2) using stratified randomization according to age, gender, and IQ. All children underwent pretesting ( $\mathrm{T} 1$; see Measures section), diagnostic testing, four preliminary sessions of HRV-BFB, 12 additional training hours of either HRV-BFB (Group 1) or HRV-BFB + MRS-NFB (Group 2) via "DVD Training Sessions" (see HRV-BFB and HRV-BFB + MRS-NFB ("DVD") Training section), and finally posttesting (T2; see Measures section). See Figure 1 for a complete study flow.

Preliminary HRV Biofeedback Training. Subjects in both Group 1 and Group 2 underwent four preliminary HRV-BFB training sessions utilizing Thought Technology Ltd. (Quebec, Canada) equipment and software (BioGraph Infiniti 6.0). A 5min HRV baseline was recorded at the beginning of each session. HRV-BFB sessions were modeled after procedures outlined by Lehrer, Vaschillo, and Vaschillo (2000).

In the beginning of the first session, participants were taught a diaphragmatic breathing technique by a trained research associate. The research associate would first model "belly breathing" by placing one hand on their stomach and the other on their chest, breathing so that "only the hand on the stomach goes up and down." This behavior was then imitated by participants while being continuously shaped and positively reinforced through verbal praise, breaks, and preferred items (e.g., playing with their iPad).

In sessions $1-4$, participants were connected to an electrocardiograph (EKG) and respiratory measurement devices, which displayed their heart rate $(\mathrm{HR})$ and respiratory patterns on a computer screen. They were asked to breathe diaphragmatically along with a visual breathing pacer, while they received visual feedback of their HR going up and down, with each inhale and exhale, respectively (i.e., "variability" in HR). Children were verbally praised for following the breathing pacer and creating more variability in their HR. The goal was to find each child's unique resonant frequency (RF) breath rate (4.5-7.0 bpm; Lehrer et al., 2000); once this was found, children would continue to breathe at this rate (some children were slightly above the 4.5-7.0 bpm range as they could not breathe this slowly and were maintained at the slowest comfortable rate). Sessions lasted an hour each. Each session was broken down into 3 or 4 diaphragmatic breathing segments of 10 to 20 minutes. In between segments 5 -min breaks were given in which participants were positively reinforced (e.g., verbal praise) and/or negatively reinforced (e.g., simply taking a break). Over the course of the four sessions, participants' breathing was shaped to improve the quality or speed, and/or find their RF rate.

HRV-BFB training in the lab was supplemented with RF diaphragmatic breathing practice at home. Parents were encouraged to practice with their child for 10 to 20 minutes per day, preferably before bedtime and/or in the morning. Apps for phones and iPads were suggested (e.g., MyCalmBeat, Breathe2Relax) to help simulate the breathing pacer utilized during lab sessions. From the first week to posttesting, parents completed a weekly breathing practice log that tracked the amount of time practiced each week. See Figure 2 for an illustration of HRV-BFB sessions. 


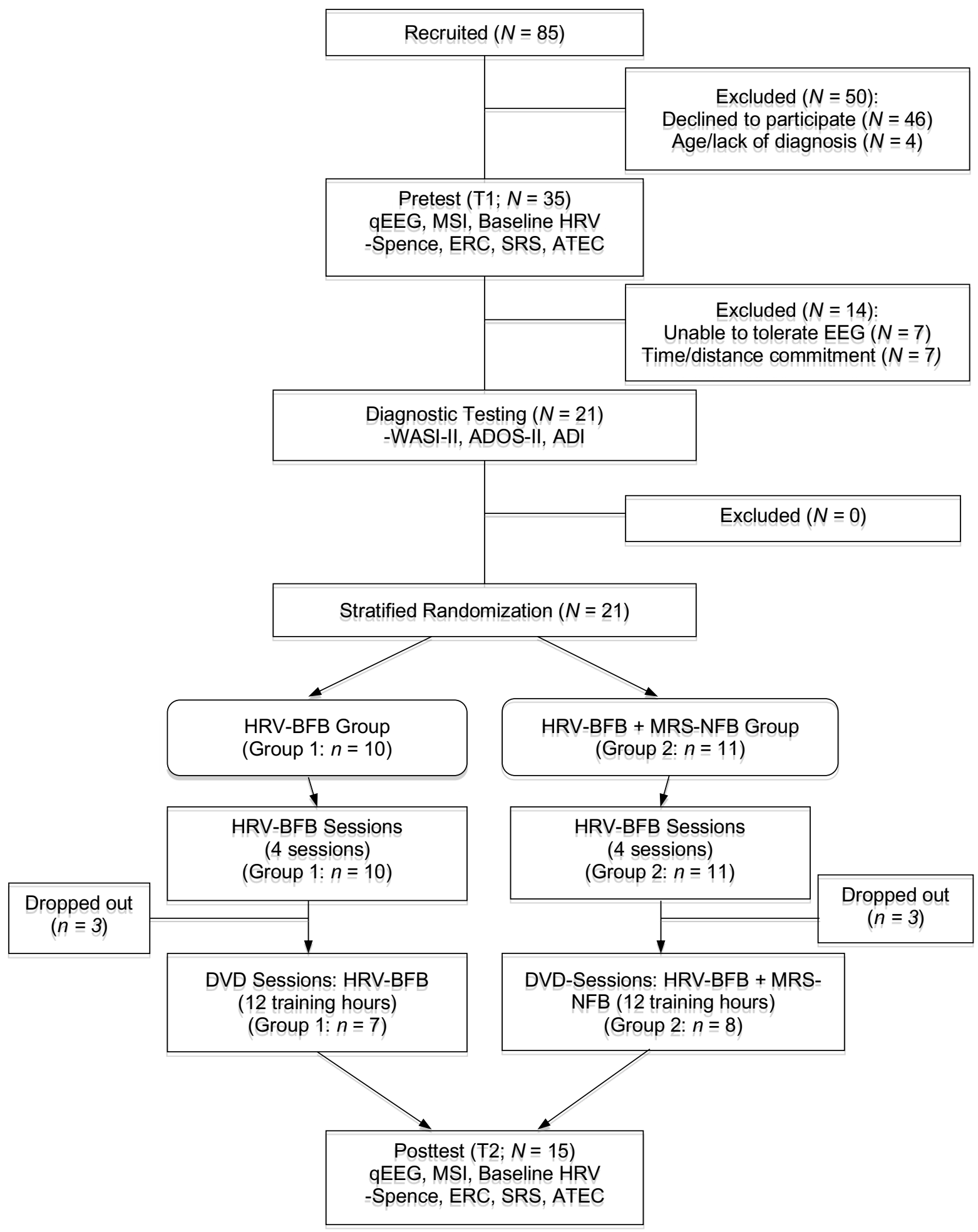

Figure 1. CONSORT Flow Diagram. Note: Pretesting was performed before diagnostic testing to ensure that children could tolerate the EEG procedure (e.g., gel, electrode placement) before using resources for diagnostic testing; stratified assignment was performed after diagnostic testing because IQ was used to match participants. qEEG = Quantitative EEG; MSI = Mu Suppression Index; Spence = Spence Anxiety Scale; ERC = Emotion Regulation Checklist; SRS = Social Responsiveness Scale; ATEC = Autism Treatment Evaluation Checklist. 


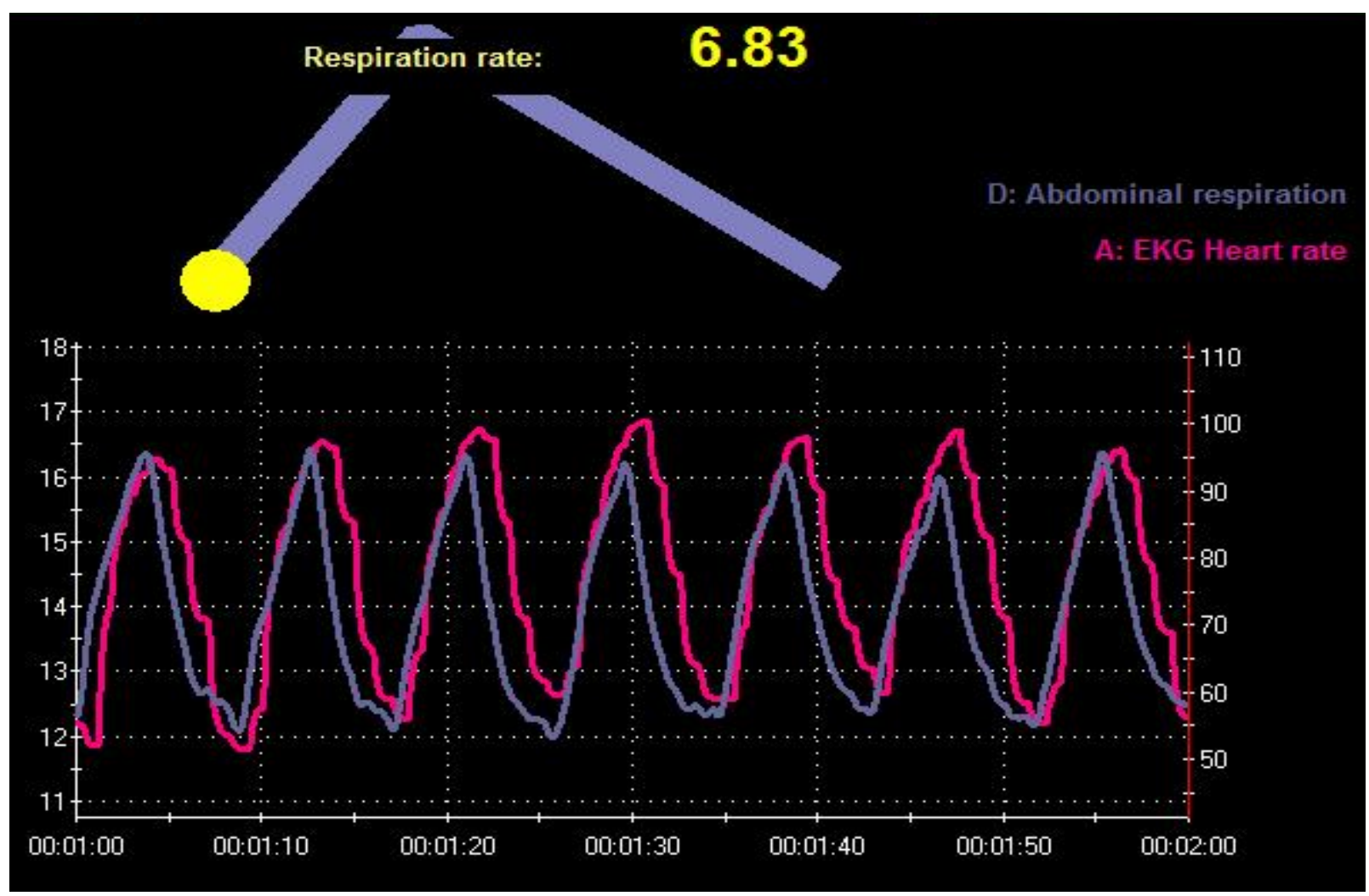

Figure 2. HRV Biofeedback Sessions. During HRV-BFB sessions, participants would breathe at their resonant frequency (RF) rate using a visual pacer (top) while receiving real-time visual feedback of their respiratory (blue) and cardiac (red) rhythms. Participants were verbally reinforced for producing large "peaks and valleys" (i.e., greater respiratory sinus arrhythmia [RSA]) and cardiorespiratory synchrony (i.e., overlapping blue and red lines). Resonant frequency (RF) breath rate was determined by calculating which breath rate (between 4.5 and 7.0 bpm) produced the largest RSA (i.e., peak-to-valley difference).

HRV Biofeedback Modifications. One participant (Group 2) required an additional (fifth) HRVBiofeedback session due to experiencing nosebleeds and lightheadedness. With modifications, they still received the same $4 \mathrm{hr}$ of HRV-Biofeedback training.

\section{HRV-BFB and HRV-BFB + MRS-NFB (“DVD”) Training.}

Basic Design. Group 1 and Group 2 both completed $12 \mathrm{hr}$ of "DVD" training using Thought Technology Ltd. (Quebec, Canada) equipment and software (BioGraph Infiniti 6.0). Participants brought a DVD movie from home or chose one in the lab, which served as the means for BFB and/or NFB reinforcement (see Group 1 Design and Group 2 Design sections). Prior to each DVD session, both groups underwent a 5-min HRV baseline recording. Additionally, a 1-min EEG baseline was taken from electrode C4 (sensorimotor cortex) to determine resting alpha $\mathrm{mu}(8-13 \mathrm{~Hz})$ activity.
Group 1 Design (HRV-BFB "DVD" Training). For Group 1 the software was programmed to respond to the participant's RF diaphragmatic breathing threshold (determined during the four preliminary HRV Biofeedback training sessions). The DVD would play if the participant was breathing at or below the determined threshold. If their breath rate exceeded the threshold, the DVD would pause and not resume until the target rate was achieved again. Thus, participants were positively reinforced for RF breathing and negatively punished for faster breathing. Every 15 to 20 minutes, 5- to 10-min breaks were provided. See Figure 3 for a visual representation of the Group 1 training sessions.

Group 2 Design (HRV-BFB + MRS-NFB "DVD" Training). As with Group 1, RF diaphragmatic breathing thresholds determined whether the DVD would play (at or below RF rate) or pause (above RF rate). Additionally, participants in Group 2 were 
reinforced for raising alpha $\mathrm{mu}(8-13 \mathrm{~Hz})$ levels over C4. An initial alpha mu threshold was set according to the resting alpha mu values obtained during the one-minute EEG baseline. When alpha mu levels were below this threshold, the video on the screen would shrink in size, making the picture more difficult to see; when alpha mu levels exceeded this threshold, the video picture would grow in size. Thus, in addition to reinforcement and punishment for RF breathing, participants were positively reinforced for raising alpha levels and negatively punished for decreasing alpha mu levels. See Figure 3 for a visual representation of the Group 2 training sessions.

\section{Group 1 (HRV-BFB Only)}

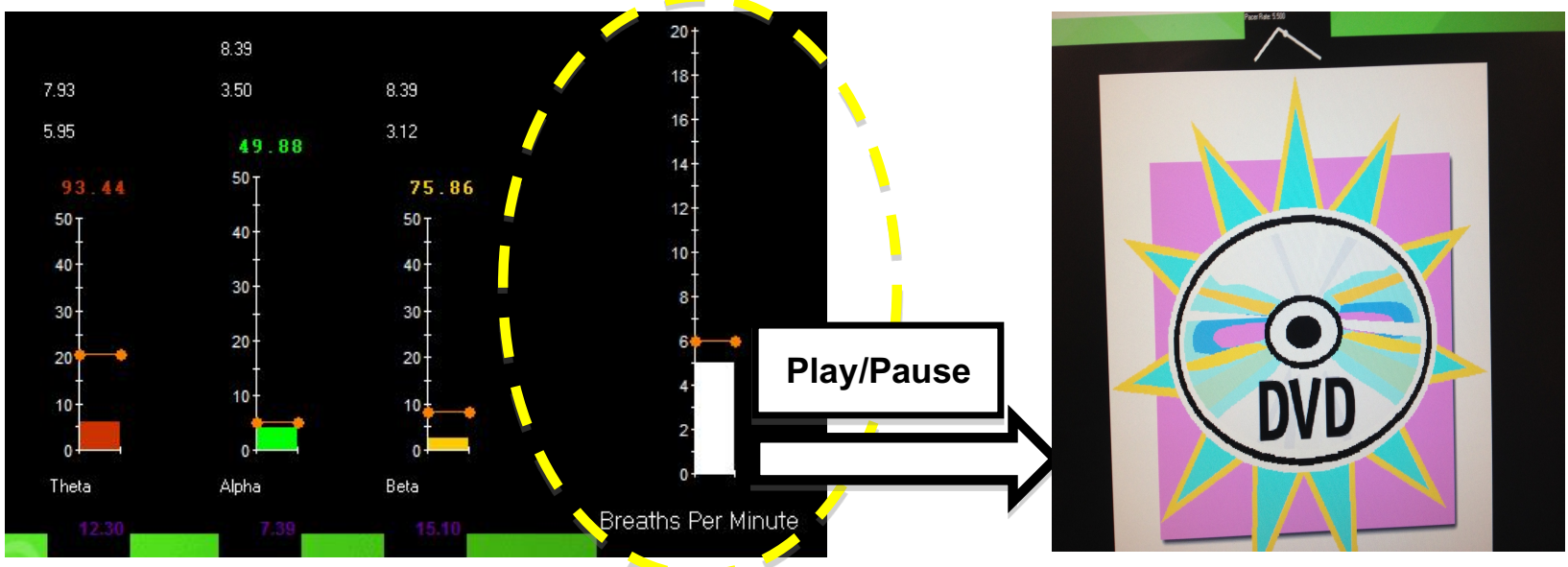

\section{Group 2 (HRV-BFB + MRS-NFB)}

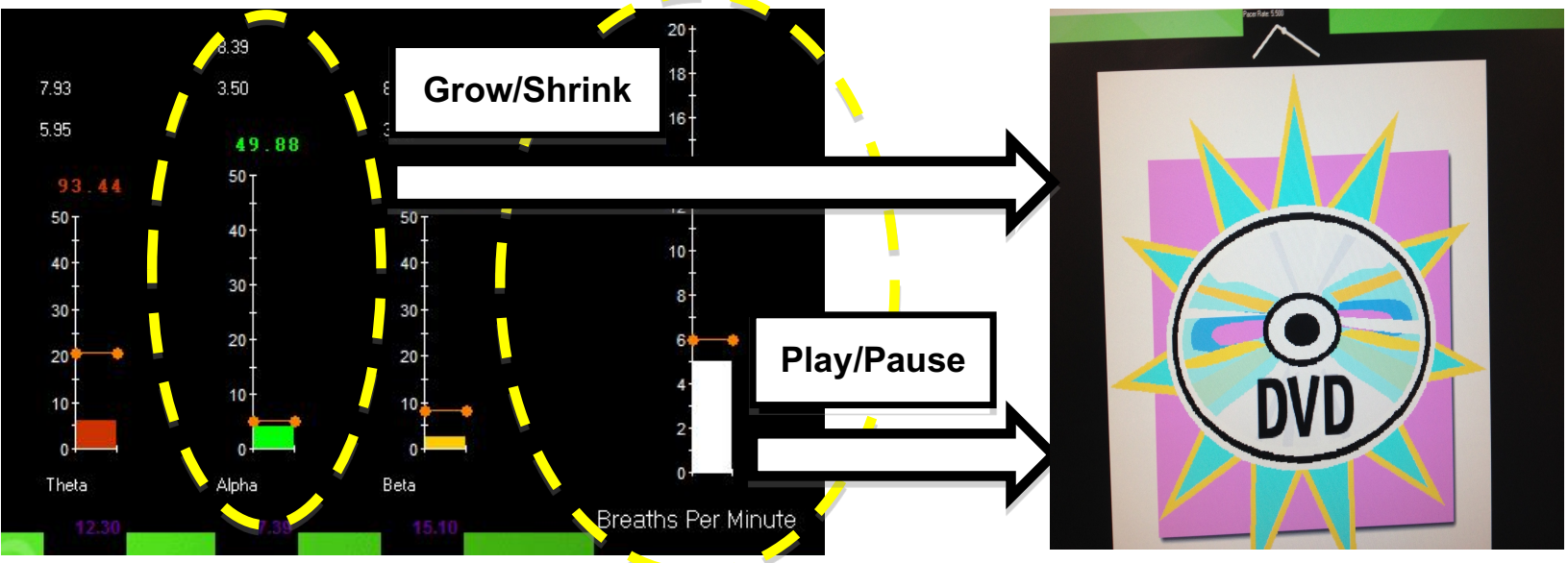

Figure 3. For participants in Group 1 (HRV-BFB Only), the movie on the screen would play only if they were breathing at or below the designated "breaths per minute" threshold, which was set at their resonant frequency (RF) pace. For participants in Group 2 (HRV-BFB + MRS-NFB), the same breathing conditions applied as in Group 1; however, for participants in Group 2, the movie screen would also grow or shrink depending on whether they exceeded or failed to meet alpha/mu $(8-12 \mathrm{~Hz})$ rhythm thresholds. 
Modifications: Session Length and Mu Thresholds. The study began with six participants (Group 1: three participants; Group 2: three participants) undergoing DVD training in 1-hr sessions, twice a week, for 6 weeks. From this point, the remaining nine participants (Group 1: four participants; Group 2: five participants) underwent DVD training sessions in 2-hr sessions, once a week, for 6 weeks. This alteration was made in order to address the issue of participant retention, as many families found it difficult to attend the laboratory twice per week. Still, all participants in Group 1 and Group 2 received a total of 12 training hours over the course of 6 weeks. One participant (Group 2) struggled with the time length of the 2-hr sessions, so they were switched back to 1-hr sessions.

During DVD training sessions for Group 2, the first three participants utilized a fixed alpha mu threshold (i.e., the DVD shrank/grew in relation to a static threshold). For the additional five participants in Group 2, the alpha mu threshold was continuously modified over the course of the session to ensure that participants were being rewarded $70 \%$ to $80 \%$ of the time within the session. This adjustment was made to strengthen the learning curve due to concerns about within-session learning.

\section{Measures}

Quantitative EEG (qEEG). EEG recording was conducted using a Biosemi ActiveTwo 32-channel, 24-bit resolution EEG data acquisition system, with semiactive electrodes. Following the EEG capping procedure, participants were moved into an electrically shielded, sound-attenuating chamber where the various assessments took place. During both T1 (pretest) and T2 (posttest) assessments, participants were asked to sit quietly for 10 min with their eyes closed, then for another 10 min with their eyes open while EEG was recorded.

Mu Suppression Index (MSI). The MSI was developed and used in previous NFB experiments (Oberman et al., 2005; Pineda et al., 2008) to evaluate mu rhythm activity over the sensorimotor cortex. Subjects are shown five different types of motion videos and are also asked to perform one instance of self-movement. The five different types of motion include: (1) Random motion: dots of different colors moving across the computer screen, (2) Non-biological human motion: a point-light walker doing jumping jacks, (3) Biological human motion: a hand making a "duck" movement, (4) Biological goaldirected motion: a hand taking a crayon out of a box, and (5) Socially-relevant biological motion: three individuals passing around a ball, where the ball is periodically tossed towards the camera making it seem as if the subject were included in the activity. For the self-movement (6), subjects were prompted by a screen to make a "duck" movement with their hand, bringing digits 2 to 5 to the thumb and opening again, repeatedly.

The random motion condition (1) constitutes a baseline where little mu suppression is expected and is thus used as a baseline for resting mu activity. The remaining conditions (2-5) represent a continuum whereby mu suppression should increase, respectively, as motion becomes more biological and meaningful. The self-movement (6) condition is expected to produce the most mu suppression (given that the subject is producing a motor action) and is used as a reference for mu suppression. See Figure 4 for a visual representation of the MSI.
(6)

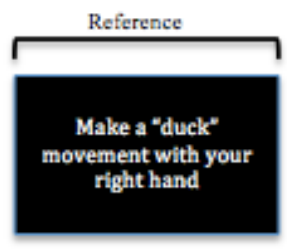

(3)

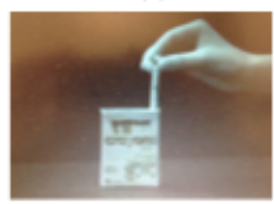

(4)
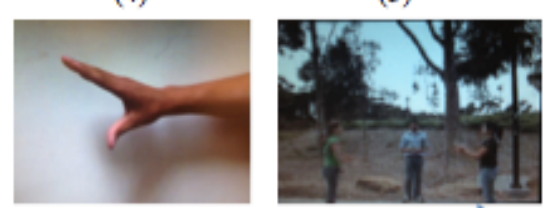

Mu Suppression

Figure 4. Mu Suppression Index. Subjects view six different stimuli, each lasting 1 min (repeated twice). As motion becomes more biological and meaningful, more mu suppression is expected. 
Heart Rate Variability (HRV). HRV was recorded using Thought Technology Ltd. (Quebec, Canada) equipment and software (BioGraph Infiniti 6.0). During both T1 (pretest) and T2 (posttest), resting HRV was measured during the 20-min qEEG recording (see Quantitative EEG section). Resting HRV was also measured before each HRV-BFB (see Preliminary HRV Biofeedback Training section) and DVD training session (see HRV-BFB and HRVBFB + MRS-NFB ("DVD") Training section) for 5 min. Specifically, data were extracted within the following domains: the standard deviation of $\mathrm{NN}$ ("normal-to-normal" wave) intervals (SDNN), the square root of the mean squared difference of successive NN intervals (RMSSD), and the highfrequency band. SDNN and RMSSD are overall indicators of HRV. The HF spectrum is the power (area under the curve) in each of the 5-min segments in the range from .15 to $.40 \mathrm{~Hz}$ and reflects parasympathetic activity. The natural log of HF (InHF) is a common index of vagal tone (Task Force of the European Society of Cardiology and the North American Society of Pacing and Electrophysiology, 1996).

\section{Social Responsiveness Scale-2 (SRS-2;} Constantino, 2012). The SRS-2 is a 65-item questionnaire used to identify social impairments often associated with ASD. For this study, all subjects were evaluated using the School-Age Form for ages 4-18, completed by the subject's parent. There are five subscales: Social Awareness (SA), Social Cognition (SCog), Social Communication (SCom), Social Motivation (SM), and Restricted Interests and Repetitive Behavior (RRB), plus the Total Score. Items are on a 4-point Likert scale $(1=$ Not True; 4 = Almost Always True) and contain questions such as "expressions on his or her face don't match what he or she is saying" and "has an unusually narrow range of interests." $T$-scores of 59 and below are considered socially typical; $60-65$ is considered mild social impairment; $66-76$ is considered moderate social impairment; and 76 or higher is interpreted as severe social impairment. Research with large standardized samples has shown high internal consistency $(\alpha=.95)$ and good reliability and validity (Bass, Duchowny, \& Llabre, 2009; Constantino et al., 2003). In the current study, internal consistency using Cronbach's alpha was .89 and .69 for pre- and posttests, respectively.

Emotion Regulation Checklist (ERC; Shields \& Cicchetti, 1997). The ERC Parent report measure is a 24-item measure of children's emotion regulation skills. The checklist includes both positively and negatively weighted items rated on a 4-point Likert scale (1 = Rarely/Never; 4 = Almost always). The ERC is divided into two scales: Emotion Regulation (ER; e.g., "is a cheerful child") and Emotional Lability/Negativity (LN; e.g., "exhibits wide mood swings"). Higher ER scores indicate superior emotion regulation; higher LN scores indicate higher emotional lability and negativity, or inferior emotion regulation. The ERC is a wellstandardized inventory and shows strong convergence with other more established behavioral measures (e.g., Child Behavior Checklist; Shields \& Cicchetti, 1997). In the current study, internal consistency using Cronbach's alpha was .54 and .45 for pre- and posttests, respectively.

Spence Children's Anxiety Scale (SCAS-Parent Report; Nauta et al., 2004; Spence, 1998). The SCAS is a 39-item parent-report questionnaire. It is used to assess anxiety symptoms across six subscales: Panic/Agoraphobia (PA), Separation Anxiety (SA), Physical Injury Fears (PIF), Social Phobia (SP), Obsessive-Compulsive symptoms $(\mathrm{OC})$, and Generalized Anxiety (GA). Items are rated on a 4-point Likert scale $(1=$ Never, $4=$ Always). The SCAS yields a total score and individual subscale scores. Lower scores on all scales are indicative of less anxiety. Good internal consistency has been indicated with Spearman Brown coefficients for each subscale ranging from 0.80-0.92 (Nauta et al., 2004). In the current study, internal consistency using Cronbach's alpha was .85 and .91 for pre- and posttests, respectively.

Autism Treatment Evaluation Checklist (ATEC; Rimland \& Edelson, 1999). The ATEC is a 77-item parent-report questionnaire consisting of four subscales: Speech/Language/Communication (SLC), Sociability (SOC), Sensory/Cognitive Awareness (SCA), and Health/Physical/Behavior (HPB). For the SLC section (e.g., "knows 10 or more words"), items are rated $N=$ Not true, $S=$ somewhat true, and $V=$ Very true. Items on the SOC (e.g., "no eye contact") and SCA (e.g., "is aware of danger") subscales are rated $N=N o t$ descriptive, $S=$ Somewhat descriptive, and $V=$ Very descriptive. For the HPB subscale (e.g., "has an extremely limited diet"), items are rated $N=$ Not a problem, $M I=$ Minor problem, $M O=$ Moderate problem, and $S=$ Serious problem. Responses are entered via an online scoring form, which produces scores for each subscale as well as a total score. For the ATEC, a higher score is indicative of more autistic severity. Previous research had shown high reliability, validity, and internal consistency $(\alpha=.94)$, and convergent validity with cognitive and behavioral functioning on other established scales such as the Wechsler Intelligence Scale for Children-IV (WISC- 
IV; Geier, Kern, \& Geier, 2013; Magiati, Moss, Yates, Charman, \& Howlin, 2011).

\section{Data Analysis}

Data Entry and Cleaning. Behavioral questionnaires were scored and entered by two independent research associates. HRV data were analyzed using Kubios version 2.2 (Biosignal Analysis and Medical Imaging Group, University of Eastern Finland, Kuopio, Finland). Smooth priors trend analysis was applied to all HRV samples. Artifacts were manually inspected and cleaned using automatic artifact rejecting. SDNN, RMSSD, and HF $(.15-.40 \mathrm{~Hz})$ were extracted; HF was then normalized using the natural log (InHF). For subjects whose HRV was measured twice per week, data were averaged to create a single value for that week. Thus, all participants had weekly baseline HRV values. To compile a score of how often participants practiced their breathing at home, total minutes practiced each day were added up into a weekly total, which was summed across weeks.

EEG Analysis. Resting baseline qEEG data were cut into 2-sec epochs, resampled at $512 \mathrm{~Hz}$, and log transformed. Fast Fourier Transform (FFG) absolute power values (uV Sq) for delta $(1-4 \mathrm{~Hz})$, theta $(4-8$ $\mathrm{Hz})$, low alpha/mu (8-10 Hz), high alpha/mu (10-12 $\mathrm{Hz})$, beta $(12-25 \mathrm{~Hz})$, and gamma $(30-40 \mathrm{~Hz})$ were computed in channel space using NeuroGuide software (Applied Neuroscience).

Raw data were also analyzed to determine significant neural oscillations within the frequency band of interest, namely mu band $(8-12 \mathrm{~Hz})$. From this, a mu suppression index (MSI) was computed. The MSI data from the video conditions were appended, resampled to $256 \mathrm{~Hz}$, and mu power extracted. To control for individual differences in scalp thickness and electrode impedance, a ratio was used: $\mathrm{MSI}=\log [\mathrm{Mu}$ Power (experimental/baseline)].

EEG Independent Component Analysis. EEG data were analyzed using the EEGLAB toolbox (Delorme \& Makeig, 2004) for MATLAB. These data were processed using a preprocessing pipeline that removed artifactual (non-brain) signals originating from head movements, muscle twitches, eye blinks, heart rate, and line noise. The pipeline used a standardized script of EEGLAB functions to automatically remove these artifacts from the EEG data. Each dataset was initially run through an impulse response filter (FIR filter) with low and high pass frequencies set to 0.5 and $40 \mathrm{~Hz}$, respectively. The channel-space data was then re-referenced to a computed average reference of the entire set of electrodes being recorded and channels assigned to the locations based on a standardized head model. Afterwards, the continuous data were visually inspected and unsuitable portions rejected. The data were then separated into suitable short epochs $(\sim 1 \mathrm{sec})$. An ICA was performed on these epochs to derive their independent components. Semiautomated and visual inspection-based rejection of data epochs on the derived components was then performed. This involved the use of the tools/component option in EEGLAB and the use of absolute voltage to determine power density spectra above zero in low frequencies, which likely reflected eye movements (coupled with scalp distribution to make sure it is centered frontally). Similarly, low frequency plus beta $(>30 \mathrm{~Hz})$ was used as an indicator of muscle activity (coupled with scalp distribution centered laterally near ears or posteriorly for neck muscle movement). We further computed two markers for every component to examine the kurtosis (high kurtosis is typical of artifacts), entropy (low values are typical of artifacts) so that those with higher kurtosis and local low entropy were marked for rejection. Following rejection of the selected data epochs, we performed ICA a second time on the pruned collection of short data epochs-this improved the quality of the ICA decomposition, revealing more independent components accounting for neural, as opposed to mixed artifactual activity. The ICA unmixing and sphere matrices were then applied to (longer) data epochs from the same continuous data. Longer data epochs were useful for time/frequency analysis and are desirable for tracking other slow dynamic features.

Missing Data and Outliers. All missing data (behavioral, HRV, and EEG) were handled by a mean imputation. One participant was missing data on the Spence Anxiety Scale (T1, Group 2). One participant's scores were replaced with the group total mean at both T1 and T2 on the ATEC due to an error in recording (Group 2). Means were imputed for HRV data for two participants at week 1 (both groups); one participant at week 3 (Group 1); one participant at week 5 (Group 1); and one participant at week 6 (Group 1) due to poor signal collection. Two participants (Group 2) were missing breathing practice time logs, and they were excluded from analyses involving breathing practice time. Outliers were assessed by calculating $z$-scores and windsorizing data beyond 2.50 standard deviations from the mean; no outliers, however, were found within this range. 


\section{Results}

The assumption of normality was tested for all variables using the Kolmogorov-Smirnov test. A small minority of variables violated this assumption $(p>$.05). Data were not transformed due to the robust nature of the statistical tests performed, with the exception of MSI data, which were transformed into the log of the ratio to normalize it. Homogeneity of variance was assessed using Levene's test. A small minority of variables violated this assumption across behavioral measures $(p>.05)$; and a large portion of variables violated this assumption across HRV indices $(p>.05)$. To normalize HRV data, a $\log 10$ transformation was attempted; however, this corrected only a minority of variables. Thus, all data were left in their original form and relied on the robust nature of the statistical tests performed.

Baseline Group Differences. An independent samples $t$-test revealed no significant differences between groups on any diagnostic features (ADOS2, ADI-R, and WASI-II) at baseline, except on the nonverbal communication subscale of the ADI-R, $F(12)=.912, p=.024$, such that Group 2 scored higher (i.e., less adaptive; see Table 2). There were also no significant differences between groups in age or baseline HRV. A chi-square analysis revealed no significant differences between groups in gender, ethnicity, or medication status.

Behavioral Outcomes. A between-group repeatedmeasures ANOVA was conducted to test the hypothesis that participants in Group 2 would show greater improvements on the ERC, Spence, SRS, and ATEC than those in Group 1 (see Table 3). A main effect for time was seen on the ERC Lability/Negativity scale, $F(1)=7.30, p=.018, \eta^{2}$ $=.359$ and the SRS Total Score, $F(1)=18.56, p$ $=.001, \eta^{2}=.588$, indicating improvements over time in emotional lability/negativity and social behavior when both groups were collapsed. There was also a trend towards a significant main effect of time on the ERC Emotion Regulation scale, $F(1)=4.41, p$ $=.056, \eta^{2}=.253$ and a nearly significant main effect of time on the ATEC Total Score, $F(1)=4.59, p$ $=.052, \eta^{2}=.261$. There were no significant group $X$ time interactions on the ERC, Spence, SRS, or ATEC $(p>.05)$, suggesting that Group 1 did not differ from Group 2 over time on any of these variables.

Given the initial hypothesis that both Groups 1 and 2 would show improvements in the ERC, Spence, SRS, and ATEC over time, a within-group repeatedmeasures ANOVA was conducted on each group (see Table 3). In Group 1, there was a significant increase on the ERC Emotion Regulation scale from T1 $(M=21.57, S D=1.81)$ to $\mathrm{T} 2(M=24.29, S D=$ 2.22), $F(1)=6.26, p=.046, \eta^{2}=.511$, indicating improvements in emotion regulation. Group 1 also showed a significant reduction in the SRS Total Score from T1 $(M=80.57, S D=8.48)$ to $\mathrm{T} 2(M=$ 71.57, $S D=8.06), F(1)=16.20, p=.007, \eta^{2}=.730$, indicating improvements in social behavior. There were no significant changes over time for Group 1 on the ERC Lability/Negativity scale, Spence, or ATEC $(p>.05)$. In Group 2, a significant decrease was observed on the ERC Lability/Negativity scale from T1 $(M=32.38, S D=6.28)$ to $\mathrm{T} 2(M=27.38$, $S D=5.24), F(1)=5.98, p=.044, \eta^{2}=.461$, indicating improvements in emotional lability/negativity. Group 2 also showed a significant increase on the ATEC Total Score from T1 $(M=$ $40.86, S D=19.74)$ to $\mathrm{T} 2(M=36.14, S D=20.62)$, $F(1)=6.97, p=.033, \eta^{2}=.499$, indicating improvements in autistic symptoms. There were no significant changes over time for Group 2 on the ERC Emotion Regulation scale, Spence, or SRS.

\section{Table 3}

Behavioral Outcomes Within- and Between-Groups.

\begin{tabular}{|c|c|c|c|c|c|c|c|c|c|}
\hline \multirow[b]{2}{*}{ Measure } & \multirow[b]{2}{*}{ Group } & \multirow{2}{*}{$\begin{array}{c}\mathrm{T} 1 \\
\text { Mean }(S D)\end{array}$} & \multirow{2}{*}{$\begin{array}{c}\text { T2 } \\
\text { Mean }(S D)\end{array}$} & \multicolumn{3}{|c|}{ Within group } & \multicolumn{3}{|c|}{ Between Group } \\
\hline & & & & $F$ & $p$ & $\eta^{2}$ & $F$ & $p$ & $\eta^{2}$ \\
\hline ERC & 1 & $34.71(8.64)$ & 32.71 (7.34) & 1.83 & .225 & .233 & & 268 & \\
\hline$(L N)$ & 2 & $32.37(6.28)$ & $27.38(5.24)$ & $5.98^{*}$ & .044 & .461 & 1.34 & .268 & 3 \\
\hline ERC & 1 & $21.57(1.81)$ & $24.29(2.22)$ & $6.26^{*}$ & .046 & .511 & & & \\
\hline$(E R)$ & 2 & $23.38(5.34)$ & $24.88(5.64)$ & .863 & .384 & .110 & .360 & .550 & $.0 \angle 7$ \\
\hline Spence & 1 & $1.57(2.37)$ & $1.71(2.06)$ & .023 & .884 & .004 & 060 & 797 & 005 \\
\hline$(P A)$ & 2 & $3.29(4.65)$ & $3.13(5.79)$ & .052 & .827 & .007 & .009 & .191 & 50 \\
\hline
\end{tabular}


Table 3

Behavioral Outcomes Within- and Between-Groups.

\begin{tabular}{|c|c|c|c|c|c|c|c|c|c|}
\hline \multirow[b]{2}{*}{ Measure } & \multirow[b]{2}{*}{ Group } & \multirow{2}{*}{$\begin{array}{c}\mathrm{T} 1 \\
\text { Mean }(S D) \\
\end{array}$} & \multirow{2}{*}{$\begin{array}{c}\text { T2 } \\
\text { Mean }(S D) \\
\end{array}$} & \multicolumn{3}{|c|}{ Within group } & \multicolumn{3}{|c|}{ Between Group } \\
\hline & & & & $F$ & $p$ & $\eta^{2}$ & $F$ & $p$ & $\eta^{2}$ \\
\hline \multirow{2}{*}{$\begin{array}{c}\text { Spence } \\
(S A)\end{array}$} & 1 & $3.43(2.15)$ & $3.29(3.45)$ & .034 & .859 & .006 & \multirow{2}{*}{.233} & \multirow{2}{*}{.638} & \multirow{2}{*}{.018} \\
\hline & 2 & $3.57(3.20)$ & $3.00(3.12)$ & 1.31 & .290 & .158 & & & \\
\hline \multirow{2}{*}{$\begin{array}{l}\text { Spence } \\
\text { (PIF) }\end{array}$} & 1 & $6.29(1.70)$ & $5.71(3.30)$ & .495 & .508 & .076 & \multirow{2}{*}{.030} & \multirow{2}{*}{.866} & \multirow{2}{*}{.002} \\
\hline & 2 & $4.86(3.18)$ & $4.13(2.53)$ & 1.75 & .228 & .200 & & & \\
\hline \multirow{2}{*}{$\begin{array}{l}\text { Spence } \\
\qquad(S P)\end{array}$} & 1 & $4.29(4.11)$ & $4.00(4.66)$ & .135 & .726 & .022 & \multirow{2}{*}{.394} & \multirow{2}{*}{.541} & \multirow{2}{*}{.029} \\
\hline & 2 & $4.71(3.61)$ & $3.63(2.20)$ & 1.23 & .304 & .149 & & & \\
\hline \multirow{2}{*}{$\begin{array}{l}\text { Spence } \\
(O C)\end{array}$} & 1 & $1.29(1.11)$ & $1.71(2.14)$ & .260 & .629 & .041 & \multirow{2}{*}{2.69} & \multirow{2}{*}{.125} & \multirow{2}{*}{.171} \\
\hline & 2 & $4.86(2.0)$ & $3.50(2.33)$ & 3.69 & .096 & .345 & & & \\
\hline \multirow{2}{*}{$\begin{array}{c}\text { Spence } \\
\text { (GA) }\end{array}$} & 1 & $4.00(1.83)$ & $2.57(2.15)$ & 4.84 & .070 & .446 & \multirow{2}{*}{.535} & \multirow{2}{*}{.477} & \multirow{2}{*}{.040} \\
\hline & 2 & $4.58(2.61)$ & $3.75(2.25)$ & 2.49 & .159 & .262 & & & \\
\hline \multirow{2}{*}{$\begin{array}{l}\text { Spence } \\
\text { (Total) }\end{array}$} & 1 & 20.86 (8.76) & $19.00(14.55)$ & .189 & .679 & .031 & & $5[\mathrm{~s}$ & คח \\
\hline & 2 & $25.86(12.81)$ & $21.13(14.78)$ & 3.88 & .090 & .357 & .369 & .554 & .028 \\
\hline SRS & 1 & $73.00(8.85)$ & $67.86(9.86)$ & 1.72 & .238 & .223 & 332 & 574 & 025 \\
\hline$(S A)$ & 2 & 70.12 (11.87) & $67.63(11.05)$ & .936 & .366 & .118 & .032 & .014 & $.0 \angle \Delta$ \\
\hline SRS & 1 & 78.57 (7.96) & $70.43(6.35)$ & $34.4^{\dagger}$ & .001 & .852 & 265 & 127 & 170 \\
\hline (SCog) & 2 & 71.75 (11.37) & $69.13(7.12)$ & .811 & .398 & .104 & 2.05 & .121 & .170 \\
\hline SRS & 1 & $79.57(6.66)$ & $71.14(9.62)$ & $8.16^{*}$ & .029 & .576 & 30 & 102 & 192 \\
\hline (SCom) & 2 & $71.25(10.90)$ & $69.25(7.32)$ & .789 & .404 & .101 & 3.09 & .102 & .192 \\
\hline SRS & 1 & $68.86(8.59)$ & $64.29(6.53)$ & 5.64 & .055 & .484 & 267 & 611 & ח20 \\
\hline$(S M)$ & 2 & $68.38(12.86)$ & $62.25(10.74)$ & 7.43 & .030 & .515 &.$\angle 0 T$ & .014 & $.0<0$ \\
\hline SRS & 1 & $80.71(12.91)$ & $70.14(7.11)$ & $8.76^{*}$ & .025 & .594 & 677 & 125 & 050 \\
\hline$(R R B)$ & 2 & $78.00(7.33)$ & $71.50(10.65)$ & 3.63 & .098 & .341 & $.6 / 7$ & $.4 \angle 5$ & .050 \\
\hline SRS & 1 & 80.57 (8.48) & 71.57 (8.06) & $16.2^{\star \star}$ & .007 & .730 & 75 & 121 & 171 \\
\hline (Total) & 2 & $74.38(8.56)$ & 70.38 (6.35) & 3.86 & .090 & .356 & 2.15 & .121 & $.1 / 4$ \\
\hline ATEC & 1 & $2.29(2.63)$ & $2.29(2.75)$ & .000 & 1.00 & .000 & 570 & 160 & 012 \\
\hline$(S L C)$ & 2 & $4.00(3.67)$ & $3.43(2.77)$ & 1.58 & .249 & .184 & $.5 / 9$ & .400 & .043 \\
\hline ATEC & 1 & 12.57 (3.05) & $11.00(4.08)$ & 1.37 & .286 & .186 & ח & 006 & חמת \\
\hline$(\mathrm{Soc})$ & 2 & $10.14(5.94)$ & $8.58(5.12)$ & 2.55 & .155 & .267 & .000 & .990 & .000 \\
\hline ATEC & 1 & $10.29(5.22)$ & $6.86(4.10)$ & 2.03 & .205 & .252 & 702 & 117 & 051 \\
\hline$(S C A)$ & 2 & $9.71(5.55)$ & $8.29(5.42)$ & 3.37 & .109 & .325 & .102 & .417 & .051 \\
\hline ATEC & 1 & $14.71(7.68)$ & $13.00(6.08)$ & .487 & .511 & .075 & 011 & 812 & $\mathrm{O}^{2} \mathrm{2}$ \\
\hline$(H P B)$ & 2 & $17.00(7.48)$ & $15.86(9.70)$ & .522 & .493 & .069 & .041 & .842 & .003 \\
\hline
\end{tabular}


Table 3

Behavioral Outcomes Within- and Between-Groups.

\begin{tabular}{cccccccccc}
\hline & & T1 & T2 & \multicolumn{3}{c}{ Within group } & \multicolumn{3}{c}{ Between Group } \\
Measure & Group & Mean $(S D)$ & Mean $(S D)$ & $F$ & $p$ & $\eta^{2}$ & $F$ & $p$ & $\eta^{2}$ \\
\hline ATEC & 1 & $39.86(11.14)$ & $33.14(11.87)$ & 1.57 & .256 & .208 & \multirow{2}{*}{.139} & .715 & .011 \\
(Total) & 2 & $40.86(19.7)$ & $36.14(20.60)$ & $6.97^{*}$ & .033 & .499 & &
\end{tabular}

${ }^{*} p<.05,{ }^{* *} p<.01, \dagger p<.003$ (Bonferroni correction applied for all subscales [.05/15 = .003])

$\mathrm{ERC}=$ Emotion Regulation Checklist $(\mathrm{ER}=$ Emotion Regulation; LN = Lability/Negativity); Spence = Spence Anxiety Scale $(\mathrm{PA}=$ Panic/Agoraphobia; SA = Separation Anxiety; PIF = Physical Injury Fears; SP = Social Phobia; OC = Obsessive Compulsive); SRS = Social Responsiveness Scale (SA = Social Awareness; SCog = Social Cognition; SCom = Social Communication; $\mathrm{SM}$ = Social Motivation; RRB = Restricted Repetitive Behaviors); ATEC = Autism Treatment Evaluation Checklist (SLC = Speech/Language Communication; Soc = Sociability; SCA = Sensory/Cognitive Awareness; HPB = Health/Physical/Behavior).

HRV. A between-group repeated-measures ANOVA was conducted to test the hypothesis that Group 2 would show greater improvements in HRV over time compared to Group 1. There was no main effect of time for SDNN, RMSSD, or InHF $(p>.05)$, nor any significant group $X$ time interactions for SDNN, RMSSD, or InHF ( $p>$.05).

Given the initial hypothesis that Groups 1 and 2 would both show improvements in HRV over time, a within-group repeated-measures ANOVA was conducted on each group. As shown in Figure 5, in Group 1, there were no significant changes over time for SDNN, RMSSD, or InHF $(p>.05)$. However, in Group 2, RMSSD showed significant improvements over time, $F(11)=2.04, p=.035, \eta^{2}$ $=.226$, although SDNN did not. Also in Group 2, InHF showed significant improvements over time $F(11)=2.23, p=.021, \eta^{2}=.241$.

HRV as a Function of Breathing Practice. To test whether the amount of time practicing one's breathing at home predicted changes in HRV over time, a repeated-measures ANOVA with breathing time (BT) as a covariate was run on the sample as a whole (both groups: $N=15$ ). There was a significant time $\times$ BT interaction for SDNN, $F(11)=$ $2.55, p=.006, \eta^{2}=.188$, suggesting that the amount of time spent practicing breathing at home predicted changes in HRV over time. There was also a time $x$ BT interaction for RMSSD, $F(11)=2.96, p=.005, \eta^{2}$ $=.212$. BT did not significantly predict changes in InHF over time $(p>.05)$. Groups 1 and 2 did not significantly differ in the average amount time spent practicing breathing at home.

Resting State EEG. There were no group differences in EEG power in delta, theta, and gamma bands, or any pre-post effects in the resting state conditions. However, group differences approached significance for the alpha band, $F(1,13)$ $=3.47, p=.085, \eta^{2}=.211$ with Group 2 showing a larger mean $\left(8.48 \mathrm{uV}^{2}\right)$ compared to Group 1 (5.1 $u^{2}{ }^{2}$ ). For the beta band, there was an interaction that approached significance with pre-post measures, $F(3,39)=2.41, p=.082, \eta^{2}=.156$ such that posttraining measures were larger $\left(3.93 \mathrm{uV}^{2}\right)$ than pretraining measures $\left(2.69 \mathrm{uV}^{2}\right)$. 

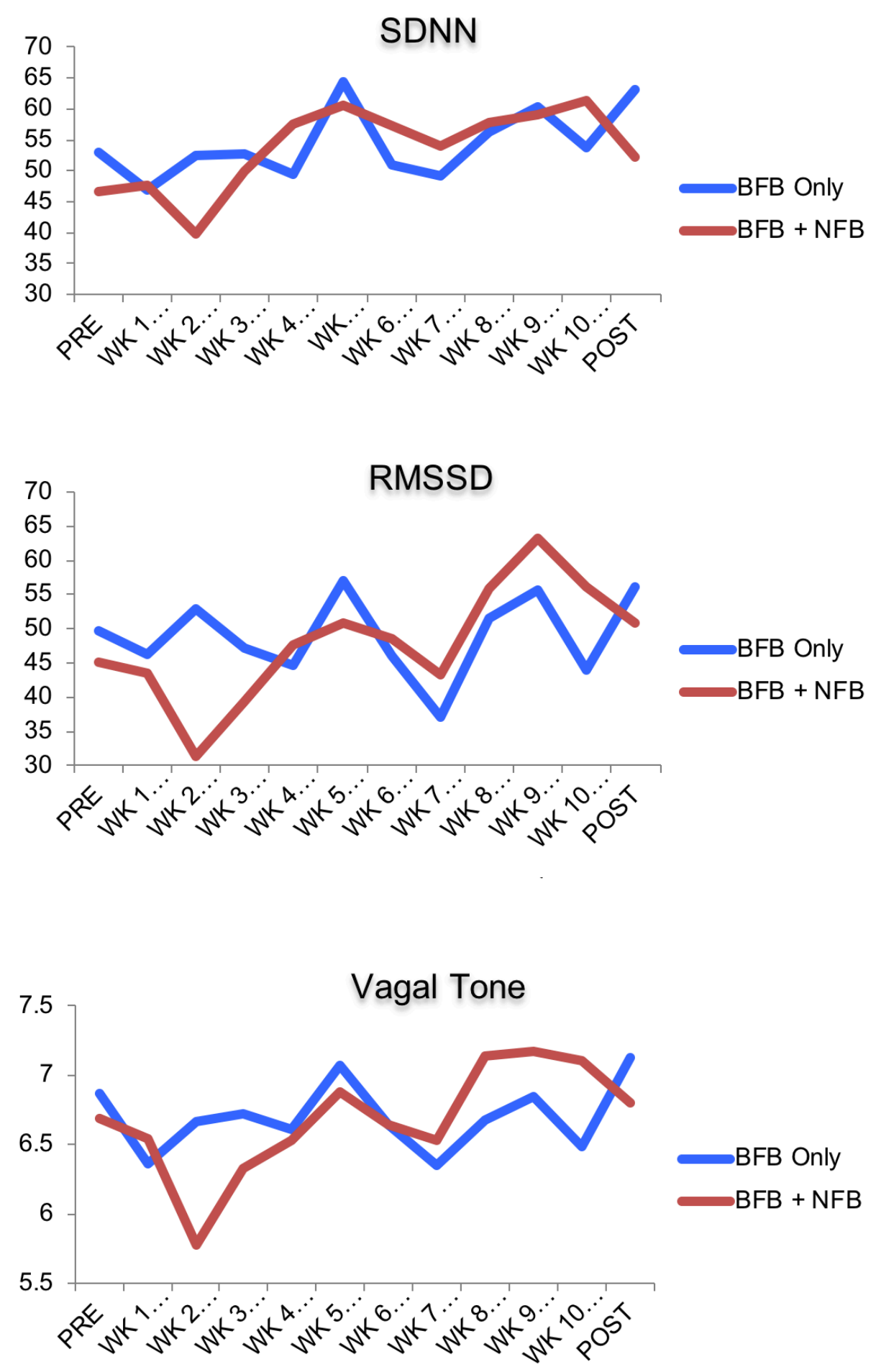

Figure 5. HRV Over the Course of Training for Groups 1 and 2. There were no significant differences between groups on SDNN, RMSSD, or vagal tone (InHF) over time. Group 1 did not show any significant changes on SDNN, RMSSD, or vagal tone over time. However, Group 2 showed significant improvements in both RMSSD and vagal tone over time. 
Mu Suppression. A mixed model ANOVA with prepost (2), videos (hands, crayons, biomotion, social, self-movement), and electrode clusters (prefrontal, frontal, central, parietal, occipital) as within-subject factors and group (Group 1, Group 2) as a between subject factor was used to evaluate changes in mu rhythm suppression. There was a main effect of pre-post measures, $F(1,13)=2.82, p=.023, \eta^{2}$ $=.340$ indicating a general reduction of $\mathrm{mu}$ suppression posttreatment $(-.051$ versus .072$)$. As shown in Figure 6, a pre-post $X$ group interaction, $F(1,13)=3.14, p=.017, \eta^{2}=.364$ showed that while Group 1 showed a small increase in mu suppression posttraining, Group 2 showed a marked reduction. As shown in Figure 7 , a highly significant pre-post $X$ clusters interaction, $F(4,52)=4.40, p=.004, \eta^{2}$ $=.253$ showed that posttreatment measurement indicated large enhancements in mu synchrony (as opposed to suppression) over central and occipital cortices.

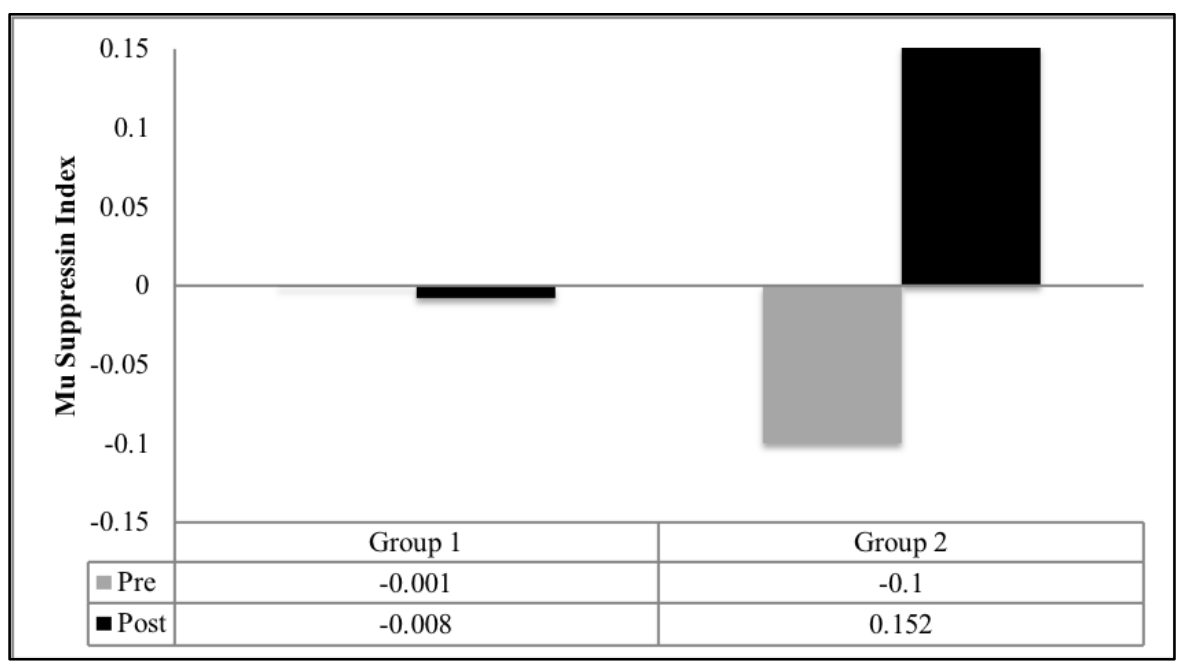

Figure 6. Effects of Training on Mu Suppression. Group 1 (HRV-BFB only) showed a small pre-post increase in mu suppression, while Group 2 (HRV-BFB + MRS-NFB) showed a marked pre-post reduction in mu suppression. Negative numbers represent more mu suppression.

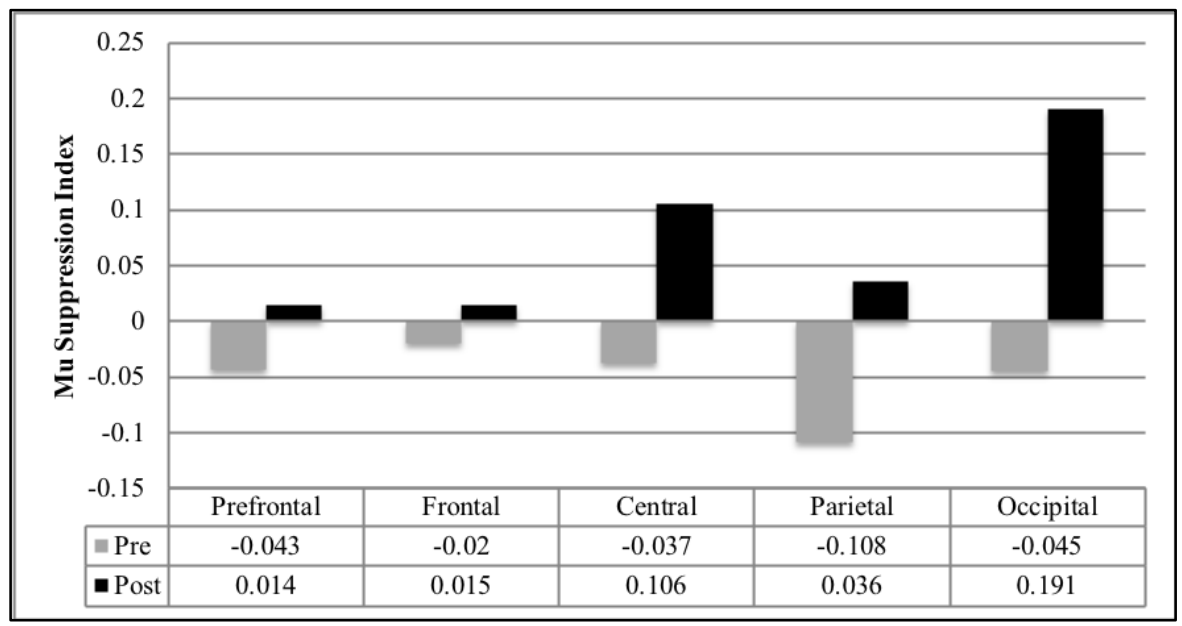

Figure 7. Training Effects on Mu Suppression Across Brain Clusters. Across both groups, the largest suppression effects were observed over frontal and parietal cortices, with posttreatment effects causing large enhancements in mu synchrony (as opposed to suppression) over the central and occipital cortices. Negative numbers represent more mu suppression. 


\section{Discussion}

The current study evaluated whether HRV-BFB improved symptoms of ASD, and whether a combined HRV-BFB + MRS-NFB approach was more efficacious than HRV-BFB alone. It was hypothesized that HRV-BFB (Group 1) would lead to improvements in social behavior, autistic symptoms, emotion regulation, anxiety, and $\mathrm{HRV}$; and that HRV-BFB + MRS-NFB (Group 2) would lead to greater improvements across each of these domains, in addition to increases in mu suppression. There were no differences between groups over time in social behavior, autistic symptoms, emotion regulation, anxiety, or HRV. However, Group 1 showed significant improvements in emotion regulation and social behavior, while Group 2 demonstrated significant improvements in emotional lability/negativity, autistic symptoms, and HRV. Significant time $X$ group differences were found in mu suppression in a pattern contrary to our hypothesis: while Group 1 showed a small increase in mu suppression, Group 2 showed a large reduction in mu suppression (i.e., a less adaptive response).

The improvements observed in ASD behaviors following MRS-NFB are consistent with previous studies, including Friedrich et al. (2015) and Pineda et al. (2008), who found improvements on the ATEC and SRS using a similar training protocol. The effect of MRS-NFB on mu suppression in this study, however, stands in juxtaposition to previous literature. The decision to reward enhancements of alpha during NFB training was based on theoretical and experimental observations that learning to enhance alpha/mu power is a prerequisite for being able to suppress it (Pineda, 2005; Pineda et al., 2008; Pineda, Friedrich, \& LaMarca, 2014). However, our results showed that rewarding alpha enhancements led to less mu suppression and greater resting alpha power. There are several possible explanations for why this may have occurred. First, it is certainly plausible that the outcomes were a direct result of the training protocol, and perhaps a reverse approach (i.e., training mu/alpha down) would be more appropriate. Friedrich et al. (2015) found that alpha enhancement training over $\mathrm{C} 4$ led to improvements in $\mathrm{mu}$ suppression over $\mathrm{C} 4$, but reductions in $\mathrm{mu}$ suppression over C3, in children with ASD during the socially-relevant biological motion task of the MSI (see EEG Analysis section); however, children who trained alpha both up and down over C4 showed an opposite pattern (i.e., decreases in mu suppression over $\mathrm{C} 4$, but increases in $\mathrm{mu}$ suppression over C3). In the current study, alpha enhancement training led to reductions in mu suppression over C4 during the socially-relevant biological motion task of the MSI. Thus, there is no clear pattern of outcomes with regard to an alpha enhancement protocol; or, it may be the case that distinct subgroups of ASD children may respond to different approaches. A second explanation is that the ability to suppress mu may require a longer period of training time than allotted in this study. While Friedrich et al. (2015) and Pineda et al. (2008) utilized 16 and $15 \mathrm{hr}$ of MNS-BFB training, respectively, the current study utilized $12 \mathrm{hr}$ of training. A third possibility is that a synergistic entrainment of alpha occurred in the HRV-BFB + MRS-NFB group, given that slow breathing may induce greater alpha due to relaxation. Previous studies have indicated a positive relationship between HRV and alpha (Casciaro et al., 2013). A fourth explanation is that the training protocol utilized was not inherently rewarding; in other words, the ability to control alpha based on DVD feedback (growing/shrinking of the screen) was not achieved, and pre-post differences were due to another variable unaccounted for. Finally, it is possible that results were skewed by poor EEG signals or the presence of artifacts during data collection. Many participants needed extensive artifact correcting due to excessive noise and signal overlap.

This is the first study to our knowledge to evaluate HRV-BFB as a potential intervention for autism. Study completion rates suggested that HRV-BFB is a feasible intervention to implement. However, there are also several barriers to using HRV-BFB in an ASD population. In the current study, several participants dropped out due to time commitment. Adjusting the frequency of laboratory visits from twice per week (1 hr each) to one per week $(2 \mathrm{hr}$ each) appeared to improve participant retention. Other potential obstacles to implementing HRV-BFB in children with ASD include age and level of functioning. Children in this study were at least nine years old and relatively high functioning; it was also anecdotally observed that younger participants, and participants lower on the spectrum, had more difficulty learning and executing the diaphragmatic breathing technique necessary for HRV-BFB. On the other hand, children who are lower functioning, and who present with lower baseline HRV, might benefit more from this intervention if they are able to learn the breathing technique: although there were no significant group differences at baseline, Group 2 had lower baseline HRV, lower IQ scores, and more severe autistic features, which might have raised 
their ceiling for improvement and contributed to the significant increases observed in HRV.

In addition to suggesting that HRV-BFB and MRSNFB are feasible interventions for ASD, this study has clinical implications beyond the use of BFB and NFB - which can be time and cost-intensive interventions. The positive effects observed in this study could potentially be due to diaphragmatic breathing practice versus BFB or NFB, per se. One finding was that children who practiced more diaphragmatic breathing at home had superior HRV outcomes. Diaphragmatic breathing teaches selfregulation of the ANS. Such changes not only influence comorbid features like emotion regulation, but also may impact social-emotional networks and improve core behavioral symptoms. For example, Uddin \& Menon (2009) suggest that ASD characteristics may stem from multiple, overlapping networks including the SN, DMN, and ECN. The anterior insula, specifically, may be responsible for switching between the DMN and ECN and is thought to contribute to social-emotional dysfunction in ASD (Menon \& Uddin, 2010; Uddin \& Menon, 2009). The insula is also part of the CAN, thus pointing to a common node between autonomic, social-emotional, executive functioning networks. Other regions in the CAN, such as the amygdala, anterior cingulate, and orbitofrontal cortex, are also key players in socialemotional and executive networks that are known to contribute to ASD symptomology (Di Martino et al., 2009; Kana et al., 2007; Sabbagh, 2004).

There were several limitations to this study, and results should thus be contextualized within these limitations. The sample size was small which may have reduced power or contributed to differential outcomes across groups. For example, since HRVBFB (Group 1) led to improvements in the SRS and emotion regulation subscale of the ERC, why didn't HRV-BFB + MRS-NFB (Group 2)-which contained the same HRV-BFB components of training-also lead to outcomes on the same scales? It is worth noting that Group 2 also showed improvements on the SRS; however, these changes were nonsignificant. Similarly, both Group 1 and Group 2 showed improvements on the ATEC; however, this effect was only significant for Group 2. A second limitation was the lack of a no-treatment control group. A comparison control group was not used in this study due to funding, resource, and recruitment limitations. It is possible that effects were simply due to time or nonspecific factors of the intervention. However, HRV tends to decrease with developmental age (Umetani, Singer, McCraty, \& Atkinson, 1998), and even the flat slope observed in
Group 1 (see Figure 5) may represent a health protective quality of HRV-BFB. Demand characteristics and parents' optimism about the intervention represent another important limitation. For parents of a child with ASD who are seeking treatment services, including "alternative" approaches such as the ones used in this study, there may be a strong bias towards positive clinical outcomes.

Although unlikely to significantly influence the results, another potential confound involved the modifications during the course of training. Six out of 15 participants completed twelve 1-hr training sessions, while the remaining nine participants completed six 2-hr sessions, with the time distribution being equal between groups. As noted earlier, this adjustment was made to enhance participant retention as it reduced the number of required lab visits. The decision to switch from a fixed reward threshold for alpha to a contingent reward threshold for Group 2 (see Modifications: Session Length and $\mathrm{Mu}$ Thresholds section) was made to enhance the NFB learning curve for Group 2. While this may have hindered or facilitated $\mathrm{mu}$ suppression/resting alpha power outcomes, this is unlikely to reverse trends or affect differences between groups, as both groups had the same HRVBFB training.

This study was the first to suggest that HRV-BFB can positively affect symptoms of ASD. Similarly, MRS-NFB - either alone or in combination with HRV-BFB - can positively influence behavioral features of ASD; however, results from this study also raise further questions about how MRS-NFB affects mu suppression, at least when combined with HRV-BFB. Future studies might test alternative training protocols (e.g., inhibiting alpha) side-by-side with the current protocol (i.e., enhancing alpha). Further research should also include control conditions, including active or "sham" NFB/BFB control groups. Finally, future studies might examine whether daily diaphragmatic breathing (without the use of technology or complicated procedures) might positively impact ASD symptoms, given that this could be a simple, cost-effective method to improve behavioral regulation in autism.

\section{Author Note}

Acknowledgements and Funding. This research was supported in part by grant funding from the ISNR Research Foundation and Foundation for Education and Research for Biofeedback and Related Sciences (FERB; \#101-2014). The authors would also like to thank the UC San Diego Academic 
Senate for funding this work (RN038B-Pineda). Finally, the authors would like to thank Richard Gevirtz for his consultation; Danielle Gomez, Asimina Courelli, Hristos Courelli, Jiaying He, Austin Lutz, Yigit Onder, Jonathan Marquez, Trisha Srivastava, Alexandra Tonnesen, Hen Caspi, Angela Swan, Mike Datko, among other Cognitive Neuroscience Lab colleagues for their help, as well as all the participants of the study and their families for their time and effort.

The authors declare that they have no conflict of interest.

\section{References}

Adolphs, R., Sears, L., \& Piven, J. (2001). Abnormal processing of social information from faces in autism. Journal of Cognitive Neuroscience, 13(2), 232-240. http://dx.doi.org /10.1162/089892901564289

American Psychiatric Association. (2013). Diagnostic and Statistical Manual of Mental Disorders (5th ed.). Washington, DC: Author.

Bal, E., Harden, E., Lamb, D., Van Hecke, A. V., Denver, J. W., \& Porges, S. W. (2010). Emotion recognition in children with autism spectrum disorders: Relations to eye gaze and autonomic state. Journal of Autism and Developmental Disorders, 40(3), 358-370. http://dx.doi.org/10.1007/s10803009-0884-3

Bass, M. M., Duchowny, C. A., \& Llabre, M. M. (2009). The effect of therapeutic horseback riding on social functioning in children with autism. Journal of Autism and Developmental Disorders, 39(9), 1261-1267. http://dx.doi.org/10.1007 /s10803-009-0734-3

Belmonte, M. K., Cook, E. H., Anderson, G. M., Rubenstein, J. L. R., Greenough, W. T., Beckel-Mitchener, A., ... Tierney, E. (2004). Autism as a disorder of neural information processing: Directions for research and targets for therapy. Molecular Psychiatry, 9(7), 646-663. http://dx.doi.org/10.1038 /sj.mp.4001499

Benarroch, E. E. (1993). The central autonomic network: Functional organization, dysfunction, and perspective. Mayo Clinic Proceedings, 68(10), 988-1001. http://dx.doi.org /10.1016/S0025-6196(12)62272-1

Bernier, R., Aaronson, B., \& McPartland, J. (2013). The role of imitation in the observed heterogeneity in EEG mu rhythm in autism and typical development. Brain and Cognition, 82(1), 69-75. http://dx.doi.org/10.1016/j.bandc.2013.02.008

Biswal, B., Yetkin, F. Z., Haughton, V. M., \& Hyde, J. S. (1995). Functional connectivity in the motor cortex of resting human brain using echo-planar MRI. Magnetic Resonance in Medicine, 34(4), 537-541. http://dx.doi.org/10.1002 /mrm.1910340409

Braadbaart, L., Williams, J. H., \& Waiter, G. D. (2013). Do mirror neuron areas mediate mu rhythm suppression during imitation and action observation? International Journal of Psychophysiology, 89(1), 99-105. http://dx.doi.org/10.1016 /j.ijpsycho.2013.05.019

Brock, J., Brown, C. C., Boucher, J., \& Rippon, G. (2002). The temporal binding deficit hypothesis of autism. Development and Psychopathology, 14(2), 209-224. http://dx.doi.org /10.1017/S0954579402002018

Casciaro, F., Laterza, V., Conte, S., Pieralice, M., Federici, A., Todarello, O., ... Conte, E. (2013). Alpha-rhythm stimulation using brain entrainment enhances heart rate variability in subjects with reduced HRV. World Journal of Neuroscience, 3(4), 213-220. http://dx.doi.org/10.4236/wjns.2013.34028

Coben, R., Linden, M., \& Myers, T. E. (2010). Neurofeedback for autistic spectrum disorder: A review of the literature. Applied Psychophysiology and Biofeedback, 35(1), 83-105. http://dx.doi.org/10.1007/s10484-009-9117-y

Coben, R., \& Padolsky, I. (2007). Assessment-guided neurofeedback for autistic spectrum disorder. Journal of Neurotherapy, 11(1), 5-23. http://dx.doi.org/10.1300 IJ184v11n01 02

Cochin, S., Barthelemy, C., Roux, S., \& Martineau, J. (1999). Observation and execution of movement: Similarities demonstrated by quantified electroencephalography. European Journal of Neuroscience, 11(5), 1839-1842. http://dx.doi.org/10.1046/j.1460-9568.1999.00598.x

Constantino, J. N. (2012). Social Responsiveness Scale, Second Edition (SRS-2). Los Angeles, CA: Western Psychological Services.

Constantino, J. N., Davis, S. A., Todd, R. D., Schindler, M. K., Gross, M. M., Brophy, S. L., ... Reich, W. (2003). Validation of a brief quantitative measure of autistic traits: Comparison of the Social Responsiveness Scale with the Autism Diagnostic Interview-Revised. Journal of Autism and Developmental Disorders, 33(4), 427-433. http://dx.doi.org /10.1023/A:1025014929212

Delorme, A., \& Makeig, S. (2004). EEGLAB: An open source toolbox for analysis of single-trial EEG dynamics including independent component analysis. Journal of Neuroscience Methods, 134(1), 9-21. http://dx.doi.org/10.1016 /j.jneumeth.2003.10.009

Di Martino, A., Ross, K., Uddin, L. Q., Sklar, A. B., Castellanos, F. X., \& Milham, M. P. (2009). Functional brain correlates of social and nonsocial processes in autism spectrum disorders: An activation likelihood estimation meta-analysis. Biological Psychiatry, 65(1), 63-74. http://dx.doi.org/10.1016 /j.biopsych.2008.09.022

di Pellegrino, G., Fadiga, L., Fogassi, L., Gallese, V., \& Rizzolatti, G. (1992). Understanding motor events: A neurophysiological study. Experimental Brain Research, 91(1), 176-180. http://dx.doi.org/10.1007/BF00230027

Enticott, P. G., Kennedy, H. A., Rinehart, N. J., Bradshaw, J. L., Tonge, B. J., Daskalakis, Z. J., \& Fitzgerald, P. B. (2013). Interpersonal motor resonance in autism spectrum disorder: Evidence against a global "mirror system" deficit. Frontiers in Human Neuroscience, 7, 218. http://dx.doi.org/10.3389 /fnhum.2013.00218

Fishman, I., Keown, C. L., Lincoln, A. J., Pineda, J. A, \& Müller, R.-A. (2014). Atypical cross talk between mentalizing and mirror neuron networks in autism spectrum disorder. JAMA Psychiatry, 71(7), 751-760. http://dx.doi.org/10.1001 /jamapsychiatry.2014.83

Friedrich, E. V. C., Sivanathan, A., Lim, T., Suttie, N., Louchart, S., Pillen, S., \& Pineda, J. A. (2015). An effective neurofeedback intervention to improve social interactions in children with autism spectrum disorder. Journal of Autism and Developmental Disorders, 45(12), 4084-4100. http://dx.doi.org/10.1007/s10803-015-2523-5

Gallese, V., Fadiga, L., Fogassi, L., \& Rizzolatti, G. (1996). Action recognition in the premotor cortex. Brain, 119(2), 593-609.

Geier, D. A., Kern, J. K., \& Geier, M. R. (2013). A comparison of the Autism Treatment Evaluation Checklist (ATEC) and the Childhood Autism Rating Scale (CARS) for the quantitative evaluation of autism. Journal of Mental Health Research in Intellectual Disabilities, 6(4), 255-267. http://dx.doi.org /10.1080/19315864.2012.681340

Hamilton, A. F. d. C. (2013). Reflecting on the mirror neuron system in autism: A systematic review of current theories. Developmental Cognitive Neuroscience, 3, 91-105. http://dx.doi.org/10.1016/j.dcn.2012.09.008 
Hill, E. L. (2004). Executive dysfunction in autism. Trends in Cognitive Sciences, 8(1), 26-32. http://dx.doi.org/10.1016 j.tics.2003.11.003

lacoboni, M. (2009). Imitation, empathy, and mirror neurons. Annual Review of Psychology, 60, 653-670. http://dx.doi.org/ 10.1146/annurev.psych.60.110707.163604

Kana, R. K., Keller, T. A, Minshew, N. J., \& Just, M. A. (2007). Inhibitory control in high-functioning autism: Decreased activation and underconnectivity in inhibition networks. Biological Psychiatry, 62(3), 198-206. http://dx.doi.org /10.1016/j.biopsych.2006.08.004

Kennedy, D. P., Redcay, E., \& Courchesne, E. (2006). Failing to deactivate: Resting functional abnormalities in autism. Proceedings of the National Academy of Sciences of the United States of America, 103(21), 8275-8280. http://dx.doi.org/10.1073/pnas.0600674103

Kouijzer, M. E. J., van Schie, H. T., de Moor, J. M. H., Gerrits, B. J. L., \& Buitelaar, J. K. (2010). Neurofeedback treatment in autism. Preliminary findings in behavioral, cognitive, and neurophysiological functioning. Research in Autism Spectrum Disorders, 4(3), 386-399. http://dx.doi.org/10.1016 /j.rasd.2009.10.007

Lehrer, P. M., Vaschillo, E., \& Vaschillo, B. (2000). Resonant frequency biofeedback training to increase cardiac variability: Rationale and manual for training. Applied Psychophysiology and Biofeedback, 25(3), 177-191. http://dx.doi.org/10.1023 IA:1009554825745

Lehrer, P., Vaschillo, E., Lu, S.-E., Eckberg, D., Vaschillo, B., Scardella, A., \& Habib, R. (2006). Heart rate variability biofeedback: Effects of age on heart rate variability, baroreflex gain, and asthma. Chest, 129(2), 278-284. http://dx.doi.org/10.1378/chest.129.2.278

Lin, G., Xiang, Q., Fu, X., Wang, S., Wang, S., Chen, S., ... Wang, T. (2012). Heart rate variability biofeedback decreases blood pressure in prehypertensive subjects by improving autonomic function and baroreflex. The Journal of Alternative and Complementary Medicine, 18(2), 143-152. http://dx.doi.org/10.1089/acm.2010.0607

Lord, C., Rutter, M., DiLavore, P. C., Risi, S., Gotham, K., \& Bishop, S. (2012). Autism Diagnostic Observation Schedule2nd Edition (ADOS-2). Torrance, CA: Western Psychological Services. https://www.wpspublish.com/store/p/2648/autismdiagnostic-observation-schedule-second-edition-ados-2

Lord, C., Rutter, M., \& Le Couteur, A. (1994). Autism diagnostic interview-revised: A revised version of a diagnostic interview for caregivers of individuals with possible pervasive developmental disorders. Journal of Autism and Developmental Disorders, 24(5), 659-685. http://dx.doi.org /10.1007/BF02172145

Magiati, I., Moss, J., Yates, R., Charman, T., \& Howlin, P. (2011). Is the Autism Evaluation Checklist (ATEC) a useful tool for monitoring progress in children with autism spectrum disorders? Journal of Intellectual Disability Research, 55(3), 302-312. http://dx.doi.org/10.1111/j.1365-2788.2010.01359.x

Mazefsky, C. A., Herrington, J., Siegel, M., Scarpa, A., Maddox, B. B., Scahill, L., \& White, S. W. (2013). The role of emotion regulation in autism spectrum disorder. Journal of the American Academy of Child \& Adolescent Psychiatry, 52(7), 679-688. http://dx.doi.org/10.1016/j.jaac.2013.05.006

McCraty, R., \& Shaffer, F. (2015). Heart rate variability: New perspectives on physiological mechanisms, assessment of self-regulatory capacity, and health risk. Global Advances in Health and Medicine, 4(1), 45-61. http://dx.doi.org/10.7453 Igahmj.2014.073

McCrimmon, A. W., \& Smith, A. D. (2013). Review of the Wechsler Abbreviated Scale of Intelligence, Second Edition (WASI-II). Journal of Psychoeducational Assessment, 31(3), 337-341. http://dx.doi.org/10.1177/0734282912467756

Menon, V., \& Uddin, L. Q. (2010). Saliency, switching, attention and control: A network model of insula function. Brain
Structure and Function, 214(5-6), 655-677. http://dx.doi.org /10.1007/s00429-010-0262-0

Nauta, M. H., Scholing, A., Rapee, R. M., Abbott, M., Spence, S H., \& Waters, A. (2004). A parent-report measure of children's anxiety: Psychometric properties and comparison with childreport in a clinic and normal sample. Behaviour Research and Therapy, 42(7), 813-839. http://dx.doi.org/10.1016/S00057967(03)00200-6

Oberman, L. M., Hubbard, E. M., McCleery, J. P., Altschuler, E. L., Ramachandran, V. S., \& Pineda, J. A. (2005). EEG evidence for mirror neuron dysfunction in autism spectrum disorders. Cognitive Brain Research, 24(2), 190-198. http://dx.doi.org/10.1016/j.cogbrainres.2005.01.014

Oberman, L. M., Ramachandran, V. S., \& Pineda, J. A. (2008). Modulation of $\mathrm{mu}$ suppression in children with autism spectrum disorders in response to familiar or unfamiliar stimuli: The mirror neuron hypothesis. Neuropsychologia, 46(5), 1558-1565. http://dx.doi.org/10.1016/j.neuropsychologia.2008.01.010

Patriquin, M. A., Lorenzi, J., \& Scarpa, A. (2013). Relationship between respiratory sinus arrhythmia, heart period, and caregiver-reported language and cognitive delays in children with autism spectrum disorders. Applied Psychophysiology and Biofeedback, 38(3), 203-207. http://dx.doi.org/10.1007 /s10484-013-9225-6

Patriquin, M. A., Scarpa, A., Friedman, B. H., \& Porges, S. W. (2013). Respiratory sinus arrhythmia: A marker for positive social functioning and receptive language skills in children with autism spectrum disorders. Developmental Psychobiology, 55(2), 101-112. http://dx.doi.org/10.1002 /dev.21002

Pineda, J. A. (2005). The functional significance of mu rhythms: Translating "seeing" and "hearing" into "doing." Brain Research Reviews, 50(1), 57-68. http://dx.doi.org/10.1016 /j.brainresrev.2005.04.005

Pineda, J. A. (2008). Sensorimotor cortex as a critical component of an 'extended' mirror neuron system: Does it solve the development, correspondence, and control problems in mirroring? Behavioral and Brain Functions, 4, 47. http://dx.doi.org/10.1186/1744-9081-4-47

Pineda, J. A., Allison, B. Z., \& Vankov, A. (2000). The effects of self-movement, observation, and imagination on $\mu$ rhythms and readiness potentials (RP's): Toward a brain-computer interface $(\mathrm{BCl})$. IEEE Transactions on Rehabilitation Engineering, 8(2), 219-222. Retrieved from http://ieeexplore.ieee.org/articleDetails.jsp?arnumber $=847822$

Pineda, J. A., Brang, D., Hecht, E., Edwards, L., Carey, S., Bacon, M., ... Rork, A. (2008). Positive behavioral and electrophysiological changes following neurofeedback training in children with autism. Research in Autism Spectrum Disorders, 2(3), 557-581. http://dx.doi.org/10.1016 /j.rasd.2007.12.003

Pineda, J. A., Carrasco, K., Datko, M., Pillen, S., \& Schalles, M. (2014). Neurofeedback training produces normalization in behavioural and electrophysiological measures of highfunctioning autism. Philosophical Transactions of the Royal Society B: Biological Sciences, 369(1644), 20130183. http://dx.doi.org/10.1098/rstb.2013.0183

Pineda, J. A., Friedrich, E. V. C., \& LaMarca, K. (2014) Neurorehabilitation of social dysfunctions: A model-based neurofeedback approach for low and high-functioning autism. Frontiers in Neuroengineering, 7, 29-34. http://dx.doi.org /10.3389/fneng.2014.00029

Porges, S. W. (2001). The polyvagal theory: Phylogenetic substrates of a social nervous system. International Journal of Psyhophysiology, 42(2), 123-146. http://dx.doi.org/10.1016 IS0167-8760(01)00162-3

Porges, S. W. (2003). The polyvagal theory: Phylogenetic contributions to social behavior. Physiology \& Behavior, 
79(3), 503-513. http://dx.doi.org/10.1016/S00319384(03)00156-2

Porges, S. W. (2007). The polyvagal perspective. Biological Psychology, 74(2), 116-143. http://dx.doi.org/10.1016 j.biopsycho.2006.06.009

Rimland, B., \& Edelson, S. M. (1999). Autism Treatment Evaluation Checklist (ATEC). San Diego, CA: Autism Research Institute.

Sabbagh, M. A. (2004). Understanding orbitofrontal contributions to theory-of-mind reasoning: Implications for autism. Brain and Cognition, 55(1), 209-219. http://dx.doi.org/10.1016 /j.bandc.2003.04.002

Schultz, R. T., Grelotti, D. J., Klin, A., Kleinman, J., Van der Gaag, C., Marois, R., \& Skudlarski, P. (2003). The role of the fusiform face area in social cognition: Implications for the pathobiology of autism. Philosophical Transactions of the Royal Society of London. Series B, Biological Sciences, 358(1430), 415-427. http://dx.doi.org/10.1098/rstb.2002.1208

Shields, A., \& Cicchetti, D. (1997). Emotion regulation among school-age children: The development and validation of a new criterion Q-sort scale. Developmental Psychology, 33(6), 906-916. http://dx.doi.org/10.1037/0012-1649.33.6.906

Shih, P., Shen, M., Öttl, B., Keehn, B., Gaffrey, M. S., \& Müller, R. A. (2010). Atypical network connectivity for imitation in autism spectrum disorder. Neuropsychologia, 48(10), 2931-2939. http://dx.doi.org/10.1016/j.neuropsychologia.2010.05.035

Siepmann, M., Aykac, V., Unterdörfer, J., Petrowski, K., \& MueckWeymann, M. (2008). A pilot study on the effects of heart rate variability biofeedback in patients with depression and in healthy subjects. Applied Psychophysiology and Biofeedback, 33(4), 195-201. http://dx.doi.org/10.1007/s10484-008-9064-z

Spence, S. H. (1998). A measure of anxiety symptoms among children. Behaviour Research and Therapy, 36(5), 545-566. http://dx.doi.org/10.1016/S0005-7967(98)00034-5

Task Force of the European Society of Cardiology and the North American Society of Pacing and Electrophysiology. (1996). Heart rate variability standards of measurement, physiological interpretation, and clinical use. Circulation, 93, 1043-1065. http://dx.doi.org/10.1161/01.CIR.93.5.1043

Thayer, J. F., \& Brosschot, J. F. (2005). Psychosomatics and psychopathology: Looking up and down from the brain Psychoneuroendocrinology, 30(10), 1050-1058. http://dx.doi.org/10.1016/j.psyneuen.2005.04.014
Thayer, J. F., Hansen, A. L., Saus-Rose, E., \& Johnsen, B. H. (2009). Heart rate variability, prefrontal neural function, and cognitive performance: the neurovisceral integration perspective on self-regulation, adaptation, and health. Annals of Behavioral Medicine, 37(2), 141-153. http://dx.doi.org /10.1007/s12160-009-9101-z

Thayer, J. F., \& Lane, R. D. (2000). A model of neurovisceral integration in emotion regulation and dysregulation. Journal of Affective Disorders, 61(3), 201-216. http://dx.doi.org/10.1016 IS0165-0327(00)00338-4

Uddin, L. Q., \& Menon, V. (2009). The anterior insula in autism: Under-connected and under-examined. Neuroscience \& Biobehavioral Reviews, 33(8), 1198-1203. http://dx.doi.org /10.1016/j.neubiorev.2009.06.002

Umetani, K., Singer, D. H., McCraty, R., \& Atkinson, M. (1998). Twenty-four hour time domain heart rate variability and heart rate: Relations to age and gender over nine decades. Journal of the American College of Cardiology, 31(3), 593-601.

Van Hecke, A. V., Lebow, J., Bal, E., Lamb, D., Harden, E., Kramer, A., ... Porges, S. W. (2009). Electroencephalogram and heart rate regulation to familiar and unfamiliar people in children with autism spectrum disorders. Child Development, 80(4), 1118-1133. http://dx.doi.org/10.1111/j.14678624.2009.01320.x

Vissers, M. E., Cohen, M. X., \& Geurts, H. M. (2012). Brain connectivity and high functioning autism: A promising path of research that needs refined models, methodological convergence, and stronger behavioral links. Neuroscience \& Biobehavioral Reviews, 36(1), 604-625. http://dx.doi.org /10.1016/j.neubiorev.2011.09.003

White, S. W., Oswald, D., Ollendick, T., \& Scahill, L. (2009). Anxiety in children and adolescents with autism spectrum disorders. Clinical Psychology Review, 29(3), 216-229. http://dx.doi.org /10.1016/j.cpr.2009.01.003

Williams, J. H. G., Waiter, G. D., Gilchrist, A., Perrett, D. I., Murray, A. D., \& Whiten, A. (2006). Neural mechanisms of imitation and "mirror neuron" functioning in autistic spectrum disorder. Neuropsychologia, 44(4), 610-621. http://dx.doi.org/ 10.1016/j.neuropsychologia.2005.06.010

Received: December 27, 2017

Accepted: January 29, 2018

Published: March 31, 2018 